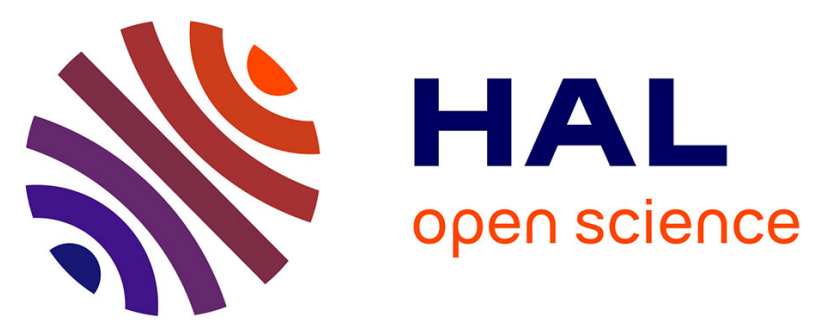

\title{
Mates matter: Gametophyte kinship recognition and inbreeding in the giant kelp, Macrocystis pyrifera (Laminariales, Phaeophyceae)
}

Carolina Camus, Maribel Solas, Camila Martínez, Jaime Vargas, Cristóbal Garcés, Patricia Gil-Kodaka, Lydia B Ladah, Ester A Serrão, Sylvain Faugeron

\section{To cite this version:}

Carolina Camus, Maribel Solas, Camila Martínez, Jaime Vargas, Cristóbal Garcés, et al.. Mates matter: Gametophyte kinship recognition and inbreeding in the giant kelp, Macrocystis pyrifera (Laminariales, Phaeophyceae). Journal of Phycology, 2021, 10.1111/jpy.13146 . hal-03148985

\section{HAL Id: hal-03148985 \\ https://hal.sorbonne-universite.fr/hal-03148985}

Submitted on 22 Feb 2021

HAL is a multi-disciplinary open access archive for the deposit and dissemination of scientific research documents, whether they are published or not. The documents may come from teaching and research institutions in France or abroad, or from public or private research centers.
L'archive ouverte pluridisciplinaire HAL, est destinée au dépôt et à la diffusion de documents scientifiques de niveau recherche, publiés ou non, émanant des établissements d'enseignement et de recherche français ou étrangers, des laboratoires publics ou privés. 


\section{MATES MATTER: GAMETOPHYTE KINSHIP RECOGNITION AND}

2 INBREEDING IN THE GIANT KELP, Macrocystis pyrifera (Linnaeus) C. Agardh ${ }^{1}$

3 Carolina Camus ${ }^{2}$

4 Centro i mar and CeBiB, Universidad de Los Lagos, Puerto Montt, Chile.

5 Maribel Solas

6 Facultad de Ciencias Biológicas, Pontificia Universidad Católica de Chile, Santiago,

7 Chile.

8 Camila Martínez

9 Centro i mar, Universidad de Los Lagos, Puerto Montt, Chile.

10 Jaime Vargas

11 Centro i mar, Universidad de Los Lagos, Puerto Montt, Chile.

12 Cristóbal Garcés

13 Centro i mar, Universidad de Los Lagos, Puerto Montt, Chile.

14 Patricia Gil-Kodaka

15 Facultad de Pesquería, Universidad Nacional Agraria La Molina, Lima, Perú.

16 Lydia B. Ladah

17 Department of Biological Oceanography, Centro de Investigación Científica y de

18 Educación Superior de Ensenada (CICESE), Ensenada, Baja California, México.

19 Ester A. Serrão

20 CCMAR, University of Algarve, Faro, Portugal. 
21 Sylvain Faugeron

22 Facultad de Ciencias Biológicas, Pontificia Universidad Católica de Chile, Santiago,

23 Chile, and UMI3614 Evolutionary Biology and Ecology of Algae, CNRS, Sorbonne

24 Université, Pontificia Universidad Católica de Chile, Universidad Austral de Chile,

25 Station Biologique, Roscoff, France.

26

$27{ }^{1}$ Date of submission and acceptance:

$28 \quad 2$ Author for correspondence: carolina.camus@ulagos.cl, +56 652322423

29

30 Running title: Inbreeding in Macrocystis pyrifera 
Inbreeding, the mating between genetically related individuals, often results in reduced survival and fecundity of offspring, relative to outcrossing. Yet, high inbreeding rates are commonly observed in seaweeds, suggesting compensatory reproductive traits may affect the costs and benefits of the mating system. We experimentally manipulated inbreeding levels in controlled crossing experiments, using gametophytes from 19 populations of Macrocystis pyrifera along its Eastern Pacific coastal distribution (EPC). The objective was to investigate the effects of male-female kinship on female fecundity and fertility, to estimate inbreeding depression in the F1 progeny, and to assess the variability of these effects among different regions and habitats of the EPC. Results revealed that the presence and kinship of males had a significant effect on fecundity and fertility of female gametophytes. Females left alone or in the presence of sibling males express the highest gametophyte size, number and size of oogonia, suggesting they were able to sense the presence and the identity of their mates before gamete contact. The opposite trend was observed for the production of embryos per female gametes, indicating higher costs of selfing and parthenogenesis than outcrossing on fertility. stable overall reproductive output. Inbreeding also affected morphological traits of juvenile sporophytes, but not their heatwave tolerance. The male-female kinship effect was stronger in high latitude populations, suggesting that females from low latitude marginal populations might have evolved to mate with any male gamete to guarantee reproductive success.

54 Key index words: fecundity, fertility, controlled crossing experiment, parthenogenesis, reproductive assurance 
Abbreviation: EPC, Easter Pacific Coast; CA-MX, California - México; PE, Perú; AT, Atacama; SC, Southern Chile; MA, Magallanes; LL, Los Lagos; P, Parthenogenesis; S, Selfing; IntraPop, crosses within population; InterPop, crosses between population; IntraHab, crosses between populations but the same habitat; InterHab, crosses between populations but different habitat.

\section{INTRODUCTION}

Reproduction is among the most studied biological processes, as it determines generational transfer of genetic material, the extent of population genetic diversity, and ultimately evolutionary trajectories of specific populations. Inbreeding, the production of offspring from the mating of individuals that are genetically more closely related than random mating, is widely reported, especially in plants. Self-fertilization in particular, i.e. mating between female and male gametes produced by the same diploid individual, is predominant in more than a third of plant species (Barrett and Harder 1996), and also occurs in animals (Jarne and Auld 2006, Charlesworth and Willis 2009). It is often associated with the negative effects of inbreeding depression (Hedrick and GarciaDorado 2016, Charlesworth and Willis 2009), which in turn may promote the evolution of inbreeding avoidance traits such as kin recognition (Szulkin et al. 2013), gamete incompatibility (Castric and Vekemans 2004, Billiard et al. 2012) or dispersal (Auld and Rubio de Casas 2013). Although inbreeding can have negative consequences, selffertilization does provide reproductive assurance when cross-fertilization is uncertain (Busch and Delph 2012), may promote the purging of deleterious alleles, might enhance the effects of background selection and genetic hitchhiking by reducing the efficiency of recombination (Roze 2016), and in some cases, can actually be adaptive if it results in inclusive fitness benefits (Puurtinen 2011). 
Inbreeding in marine organisms is poorly understood. There is considerable diversity of life cycles and mating systems in the ocean, providing a rich source of models for studying the occurrence and the consequences of inbreeding. At first glance, selfing might be thought to be rare in the ocean, considering the large number of species with planktonic larval stages resulting in long range dispersal, which most likely reduces the probability of sibling gamete encounters. However, inbreeding rates in sessile and sedentary marine species can be as high as in terrestrial plants (Olsen et al. 2020).

Marine algae are particularly interesting models for studying mating systems because of their complex life cycle, which most often includes haploid and diploid generations. Meiosis in marine algae occurs on the diploid individuals, while gametes are produced by haploid males and females or hermaphroditic individuals. One important aspect of such a life cycle is that mating between sibling males and females (i.e. those resulting from a single diploid parent) leads to the equivalent of selfing, as fertilization may occur between gametes originating from the same diploid genome. Another key aspect of seaweeds is that the dispersal capacity of spores and gametes can be as low as $<1 \mathrm{~m}$ (i.e. Postelsia palmaeformis, Wootton and Pfister 2013), and usually less than $1 \mathrm{~km}$ for spores (Santelices 1990, Kinlan and Gaines 2003). Reduced dispersal provides opportunities for mating among relatives and between sibling gametophytes. In some taxa, spores from the same parent are dispersed in mucilage or clumps and recruit together (Santelices 1990), further increasing the possibility for gametophyte selfing. Many species of marine algae show high levels of heterozygote deficiency within populations (e.g. Benzie et al. 1997, Engel et al. 2005, Krueger- Hadfield et al. 2011, Guillemin et al. 2016). Therefore, understanding whether inbreeding levels relate to limited spore dispersal or a predominantly inbred mating system, such as selfing, is important, yet has been explored very little. In some cases, paternity analyses reveal a 
complete absence of selfing besides high inbreeding levels, which was better explained by clumped spore dispersal in the red algae Chondrus crispus (Krueger- Hadfield et al. 2013) and Gracilaria gracilis (Engel et al. 2004). Yet in other cases, selfing is inferred for the hermaphroditic brown alga Fucus spiralis (Perrin et al. 2007), and for the giant kelp Macrocystis pyrifera (Johansson et al. 2013), for which population genetic simulations suggest high mortality of homozygous juveniles accompanies selfing, implying inbreeding depression.

Inbreeding depression is largely unassessed in algae. Limited evidence comes from breeding experiments revealing heterosis in between-population crosses (Westermeier et al. 2011, Zhao et al. 2016) or the monitoring of natural populations showing juvenile mortality associated with inbreeding levels (Teixeira et al. 2016). Inbreeding depression is not expected in haploid-diploid life cycles because the haploid stage may actually facilitate the purge of deleterious alleles. In this context, no restriction to selfing would be expected to evolve. Yet, empirical evidence is extremely scarce. For instance, synchronicity in gamete release differs among species with different selfing rates in the brown alga Fucus spp, with a narrower timeline of spawning in the dioic, predominantly outcrossing $F$. vesiculosus than the hermaphroditic, highly selfing $F$. spiralis and $F$. guiryi (Monteiro et al. 2012), suggesting a weaker selective constraint in selfing species. On the contrary, chemical recognition of complementary surface carbohydrates on male and female gametes has been suggested to regulate successful fertilization within, rather than between populations of Ectocarpus siliculosus (Schmid 1994).

In this study, we investigate the effects of inbreeding in a haploid-diploid seaweed, the giant kelp Macrocystis pyrifera. Kelp is a common name given to seaweeds with distinct life cycles, yet most are large brown seaweeds of the order Laminariales. Laminariales exhibit a heteromorphic haploid-diploid life cycle: the diploid individual 
(i.e. the sporophyte) can be up to $60 \mathrm{~m}$ long and form marine forests (Schiel and Foster 2015). In the giant kelp, meiosis occurs on specialized blades, the sporophylls, located at the base of the sporophyte, less than a half-meter above the substratum (Gaylord et al. 2002). This anatomical feature suggests that spores disperse very short distances from the parent sporophyte, as spores may settle within minutes after being released. Spores develop into microscopic free-living haploid individuals (i.e. gametophytes). Male gametophytes release sperm which swim to the oogonia (i.e. female gametes) sprouting on the female gametophyte. Gamete encounter is facilitated by chemical signaling from females that trigger the release and attraction of sperm (Mamer et al. 1984, Maier et al. 2001). Limited spore dispersal increases the chance of inter-gametophytic selfing (i.e. mating between female and male gametophytes produced by the same sporophyte), but also bi-parental inbreeding via outcrossing between genetically related parent sporophytes (i.e. same family members spatially clumped). Models have predicted that restoration of diploidy and the production of a juvenile sporophyte (e.g. Oppliger et al. selfing and outcrossing.

Inbreeding depression has been seldom studied in kelp species. For the sea palm P. palmaeformis, a low cost of selfing has been estimated for individual fitness (Barner 
et al. 2011), and inbreeding rates show no effect on population extinction risk (Wootton and Pfister 2013). On the contrary, the fitness of $M$. pyrifera can be dramatically reduced in selfed compared to outcrossed individuals (Raimondi et al. 2004): zygote production by the haploid gametophytes was reduced in inbred crosses, as well as survivorship, fecundity and fertility of the adult diploid offspring. The existence of heterosis when crossing gametophytes of distant populations further supports the idea of inbreeding depression within populations (Westermeier et al. 2010). This cost of selfing seems spatially variable, with some populations not expressing any costs or benefits compared to outcrossing (San Miguel 2017), likely suggesting a variable efficiency of purging among populations. However, strong inbreeding coefficients have been detected in most studied populations of the species, i.e. along the coasts of California and Chile (Johansson et al. 2013 and Camus et al. 2018, respectively).

There exist apparent inconsistencies between high inbreeding rates and high inbreeding depression in some natural populations of the giant kelp. The suspected high mortality of inbred recruits in natural populations (Johansson et al. 2013) suggests strong selection for purging deleterious alleles. It may also favor strong selection against selfing if inbreeding depression is persistent. Different traits are expected to evolve in order to reduce successful fertilization among kin gametes. Life history trait evolution has been reported in response to specific conditions in kelp species, such as increased automixis (i.e. fusion of two of the four meiotic products, producing diploid gametophytes) to increase reproductive assurance at thermal range limits of Laminaria digitata (Oppliger et al. 2014), or an increase in asexual reproduction and an unbalanced sex ratio to avoid hybrid formation in a secondary contact zone of the Lessonia nigrescens species complex (Oppliger et al. 2011, 2012). These examples highlight the 
capacity of kelps to adapt their life cycle and mating system in response to specific reproductive requirements or environmental conditions.

In this study, we experimentally manipulated the level of inbreeding using gametophytes of the giant kelp to investigate the effects of male-female kinship on 184 female fecundity and fertility, as possible indicators of prezygotic barriers to selfing in the gametophytic stage, as well as the existence of inbreeding depression in the F1 diploid progeny. The study also assesses the variability of these effects among different regions and habitats of the Eastern Pacific coast.

\section{MATERIALS AND METHODS}

Field sampling and gametophyte isolation.

191 Fertile blades were collected from 19 populations, from Lima, Peru, to Puerto Yartau, Magellan Strait, Chile (Fig. 1), covering most of the South Eastern Pacific coastal distribution range of Macrocystis pyrifera. Additional samples from Santa Cruz (California, USA), Ensenada and Punta Baja (Baja California, Mexico) were collected in the northern hemisphere as replicates of the low latitude range limits of the southern hemisphere, namely Lima, Marcona and Ilo (Peru). These sampling sites represented 5 regions identified in Fig. 1, hereafter named California and Mexico (CA-MX), Peru (PE), Atacama (AT), Southern Chile (SC) and Magallanes (MA), and are used in experiment 1 (see below). Four SC localities were selected for their contrasting demography (i.e annual and perennial) and wave exposure habitats, according to Buschmann et al. (2004, 2006), and used specifically in experiment 2 (see below): Carelmapu and Pargua are perennial and wave exposed populations located nearby two annual and wave protected populations, Ilque and Metri (Buschmann et al. 2006). These 
204 four populations defined a subgroup of SC, called hereafter Los Lagos (LL) as they were used in experiment 2.

206 In each population, 1 to 4 sporophylls (i.e. the fertile blades) per sporophyte were 207 collected and washed under freshwater to remove diatoms and other microorganisms 208 from the blade surface. Small pieces of cleaned blade were then incubated in cool, sterile seawater to stimulate spore release. Blade pieces from different sporophytes were kept separate in different flasks to isolate individual sporophyte progeny. Spores settled on glass slides and germinated into male and female gametophytes. These were cultivated in Provasoli enriched seawater (McLachlan 1973) at 10 to $12{ }^{\circ} \mathrm{C}$, under $12 \mathrm{~h}: 12 \mathrm{~h} \mathrm{~L}: \mathrm{D}$ photoperiod, at $25-30 \mu \mathrm{mol} \cdot \mathrm{m}^{-2} \cdot \mathrm{s}^{-1}$ of white light. After male and female differentiation, based on cell width and ramification pattern of the filamentous gametophytes, individual males and females were isolated with a Pasteur glass pipette and cultivated separately under the same laboratory conditions but using red light to avoid gametogenesis. After a period of vegetative growth, each gametophyte was mechanically fragmented at 5-10 cells per fragment, using a glass tissue grinder with teflon pestle or a plastic pestle, to expand their biomass. Clonal fragments of each gametophyte initially deposited in 6-well multiplates (Corning) were further transferred to increasing volume up to $50 \mathrm{~mL}$ tubes or Erlenmeyer flasks. Culture conditions were as mentioned above, but under red light until experimental crosses were conducted (see

223 Fig. 2 and Fig. S1).

Crossing experiments.

Experiment 1 aimed to explore the regional variability of female fecundity, reproductive success and inbreeding depression. Because gametophyte fertility is variable within a progeny issued from a single parental sporophyte, vegetative fragments of 5 sister females were pooled to ensure the production of gametes and successful fertilization. 
Male fragments were also pooled from 5 individual cultures originated from a single sporophyte (i.e. pool of clonal fragments of 5 sib males; Fig. 2 and Fig. S1). For CAMX gametophytes, no sib pool was made as the identity of the parental sporophyte was not registered. Therefore, single females were fragmented and crossed with single male clonal fragments. These pools or single gametophyte clonal cultures were used as basic experimental units, and subsequently subdivided into 4 aliquots. Each aliquot was either grown alone, to stimulate parthenogenesis, or in the presence of males. Parthenogenesis occurs by nucleus endoduplication within the female gamete, leading to a fully homozygous diploid sporophyte. This represents the highest possible level of inbreeding. Selfing was achieved by mixing one female aliquot with one male pool obtained from the same parental sporophyte. Within-population crosses were performed by mixing a female aliquot with a male pool obtained from a different sporophyte of the same population. Crosses among populations but within each region were performed by mixing one female aliquot with a male super-pool obtained by mixing 4 sib male pools from two different populations of the same region. Therefore, each female pool

244 produced F1 sporophytes either by parthenogenesis $(\mathrm{P})$, selfing $(\mathrm{S})$, by crosses within 245 population (IntraPop5), or between populations within region (InterPop). Two female replicates per population followed this experimental setup (e.g. 24 female pools from

247 Peru and Chile, and 6 single females from California-Mexico) leading to a total of 120 crosses.

249 The crosses were kept at a common temperature of $12{ }^{\circ} \mathrm{C} \pm 1{ }^{\circ} \mathrm{C}$ for 36 days under white 250 light to allow gametogenesis, during which fecundity, expressed as the number of oogonia per living female, and fertility, expressed as the embryogenesis rate determined

252 by the number of embryos per living female, were registered every 6 days. 253 Embryogenesis includes embryos produced by fertilized oogonia and 
254 parthenogenetically developed embryos. Data was collected using a camera (Vi1, 255 Nikon) mounted on an inverted microscope (Olympus, CKX53) on 5 optical fields $256\left(15.2 \mathrm{~mm}^{2}\right.$ each, at 10x magnification) per replicate. Digital photos were processed with 257 ImageJ software.

258 Because laboratory culture conditions might be optimal for any F1 sporophyte, the 259 differences between inbreeding and outbreeding levels are expected to be subtle. To maximize the potential of detecting differences, the F1 sporophytes were exposed to a heatwave for 5 days at $24{ }^{\circ} \mathrm{C} \pm 1{ }^{\circ} \mathrm{C}$ under white light. The sporophyte survival rate was measured on day 5 .

Experiment 2: Individual female and male gametophytes were treated independently, without pooling sibs (Fig. 2 and Fig. S1). Gametophytes were collected from 13 sporophytes per population. Each female or male clone was divided into 5 aliquots. Single female aliquots were cultured alone to stimulate parthenogenesis (P). Selfing (S) was achieved by mixing one female aliquot with one male aliquot from the same parental sporophyte. Two types of within-population crosses were performed: one female aliquot crossed with one male aliquot of a different sporophyte of the same population produced genetically identical F1 sporophytes (IntraPop1), and one female aliquot crossed with two male aliquots from different sporophytes from the same 272 population produced the equivalent of half-sib F1 sporophytes (IntraPop2). Interpopulation crosses were achieved by mixing an aliquot of 13 females with 13 males of a different population but the same habitat (IntraHab, within annual/protected or perennial/exposed populations) or the alternative habitat (hereafter InterHab).

Each cross was repeated 3 times and data were averaged. In total, 20 female pools (i.e. 5 per population) were used to replicate the different breeding types, except for InterHab which used 6 replicates, leading to a total of 106 crosses. In each of these experimental 
units, fecundity was decomposed into the length of female gametophyte, the length of oogonia and the number of oogonia per gametophyte on day 12 . Fertility was estimated as the number of embryos per female gametophyte on day 17 and the embryogenesis rate calculated as the number of embryos at day 17 over fertile females at day 12 (i.e females bearing oogonia). The length of the juvenile sporophyte, the number of blades, and the holdfast diameter were recorded on day 30 as proxies of $\mathrm{F} 1$ juvenile sporophytes fitness. Data was collected using an inverted microscope (PrimoVert, Carl Zeiss) with a Canon EOS REBEL T3 camera mounted. Counts were taken in 10 optical fields (an area of $8,13 \mathrm{~mm}^{2}$ each) per well at 40X magnification and digital photos were processed with ImageJ software. For morphological data of juvenile sporophytes, ten individuals per replicate were photographed with a scale and processed with the same image software.

\section{Statistical analyses.}

The effect of breeding type and region (in Experiment 1) or habitat (in Experiment 2) on fecundity, fertility and sporophyte growth (only in Experiment 2) were assessed by mixed linear models (Searle 1987, Pinheiro and Bates 2000) using lme4 in R (Bates et al. 2015). The breeding type, region (or habitat), and their interactions were defined as fixed effects. A female's identifier was defined as a random intercept, that is the identifier associated with the parental sporophyte of each clone or pool of gametophytes, to integrate the lack of independence of the breeding types resulting from the repeated use of each gametophyte or gametophyte pool. Mortality associated with the heatwave experiment was analyzed following the same procedure. Sporophytes from California-Mexico and Peru were excluded from the analysis because of a much lower number of individuals compared to the other regions. The response variables of experiments 1 and 2 were transformed with Yeo-Johnson (Yeo and Johnson 2000) and 
Box-Cox (Box and Cox 1964), respectively, to fulfill the assumptions of normality and homoscedasticity. Contrast of hypotheses was performed using ANOVA Type II with the Kenward-Roger approximation to adjust degrees of freedom of the denominator (Fox 2002). Pairwise comparisons were performed with the a posteriori Tukey test using multcomp in $\mathrm{R}$ (Hothorn et al. 2008), using Bonferroni correction for false discovery rates. Pairwise comparisons were performed for breeding types only, inside the region or within the same habitat in Experiment 1 and 2, respectively.

\section{RESULTS}

Female fecundity and fertility depend on male identity.

Fecundity, expressed as the production of female gametes, was significantly affected by the presence of males (Experiment 1; ANOVA: $F_{(3,75)}=11.36, p<0.0001$. Experiment 2; ANOVA $\left.F_{(5,108)}=48.40, p<0.0001\right)$ but not in the same manner for all regions tested as the interaction Breeding Type $\mathrm{x}$ Region in Experiment 1 was statistically significant $\left(\right.$ ANOVA: $\left.F_{(12,75)}=3.05, p<0.002\right)$. The highest fecundity (i.e. up to 5 oogonia per female gametophyte) was observed in both experiments for females left alone (i.e. without males), when parthenogenesis was stimulated (Figs. 3a and 4a). The lowest gamete production was observed when females were exposed to males issued from different sporophytes regardless of population origin. In Experiment 2, fecundity ranged from $66.7 \%$ in Selfing to $36.6 \%$ in IntraPop2 of the parthenogenetic values. The same pattern was observed in Experiment 1 for Southern Chile and Magallanes, with InterPop fecundity being reduced to $10 \%$ of the respective parthenogenetic value in the later region. A noticeable exception was for within-habitat interpopulation crosses in

327 Southern Chile-Los Lagos (LL), where no difference was observed with parthenogenetic females, both producing $4.0 \pm 2.5$ and $4.3 \pm 2.0$ oogonia per female, 
respectively (Fig. 4a). Fecundity, expressed as morphological characteristics of LL gametophytes revealed that the size of the vegetative parts of the female (Fig. 4b) and the size of the gametes (Fig. 4c) significantly differed when exposed to different types of males (ANOVA: $F_{(5,124)}=11.55, \quad p<0.0001 ; \quad F_{(5,127)}=57.55, \quad p<0.0001$; respectively) and among habitats (Breeding Type $\mathrm{x}$ Habitat, ANOVA: $F_{(5,164)}=2.34, p=$ $0.04 ; F_{(5,172)}=5.12, p=0.0002$, respectively). Oogonia were bigger when exposed to sib males (i.e. reaching $0.036 \pm 0.014 \mathrm{~mm}$ in length) than to males from different sporophytes or in solitary females, with differences ranging from $11.8 \%$ in parthenogenesis and 36.6\% in IntraHab crosses (Fig. 4c). Female size was the largest in the absence of males or with highly related males (around $0.2 \mathrm{~mm}$ in length), and their size progressively decreased with male-female kinship (Fig. 4b). Females in parthenogenesis, selfing and IntraPop1 crosses were 5x larger than females in presence of males from different habitats (InterHab) (Fig. 4b).

Female fertility, measured as the production of embryos per female gametophyte (available in LL populations only), was significantly explained by the male-female kinship (Fig. 4d, ANOVA: $F_{(5,126)}=11.94, p<0.0001$ ) with no effect of the factor Habitat or the interaction Habitat $\mathrm{x}$ Breeding type. Again, the highest fertility was observed in parthenogenetic females, while slightly reducing with sib-male kinship in intrapopulation crosses. However, between population outcrosses (i.e. intra and inter habitats), fertility did not differ significantly from any of the within population crosses (Fig. 4d). This pattern was explained by a higher embryogenesis rate of all but intrahabitat crosses (Fig. 4e, ANOVA: $F_{(5,117)}=24.88, \mathrm{p}<0.0001$ ). Embryogenesis higher than $100 \%$ is explained by the continuous production of oogonia when exposed to males (except for IntraHab crosses), while parthenogenetic females stopped gametogenesis after initial gamete production (i.e. until day 12). The same embryogenesis pattern was 
observed in Experiment 1 (Fig. 3b, ANOVA: Factor Breeding type: $F_{(3,71)}=26.79, \mathrm{p}<$ $0.0001)$.

Inbreeding depression in F1 progeny.

357 Male-female kinship affected different traits of the juvenile sporophytes such as sporophyte length (Fig. 5a, ANOVA: $F_{(5,82)}=21.61, \mathrm{p}<0.0001$;), number of blades (Fig. 5b, ANOVA: $\left.F_{(5,96)}=24.05, \mathrm{p}<0.0001\right)$ and holdfast diameter (Fig. 5c, ANOVA: $\left.F_{(5,92)}=32.42, \mathrm{p}<0.0001\right)$. Holdfast size was smaller in inbred sporophytes (i.e. parthenogenetic, selfing and intrapopulation) compared to other outcrossed progenies, and significant differences were observed between habitats (ANOVA: Habitat: $F_{(1,16)}=$ 5.51, $p=0.01$; Breeding Type x Habitat: $\left.F_{(5,92)}=4.21, p<0.001\right)$. However, the differences in juvenile length and blade number were largely inconsistent with parental kinship: while selfing produced the smallest values for both traits, sporophytes from intermediate levels of male-female kinship (i.e. intra-population crosses) expressed the highest values together with parthenosporophytes (Figs. 5a and 5b). Tolerance to a heat wave did not differ significantly between crosses (Fig. S2, Table S1; ANOVA: $F_{(3,45)}=$ 2.32, $p=0.09$ ), as mortality rates ranged between $80 \%$ to $99 \%$ at $24^{\circ} \mathrm{C}$. CaliforniaMexico and Peru were not included in the heat wave analysis because too few sporophytes were obtained from the crossing experiments.

Latitudinal variability of kinship effect on fecundity and fertility of female gametophytes.

The effects of male-female kinship on fecundity strongly varied among regions and habitats (Fig. 3a; ANOVA: Breeding Type $x$ Region: $F_{(12,75)}=3.05, \mathrm{p}=0.002$ ), with a significant effect detected only in Southern Chile and Magallanes regions. Both low latitude regions (i.e. California-Mexico and Peru) had a consistently low fecundity (i.e. 
378 less than 1 oogonia per female gametophyte on average) compared with Chilean regions

379 (Fig. S3, Table S2; ANOVA: Region: $F_{(4,25)}=45.76, \mathrm{p}<0.0001$ ). A similar pattern was observed in fertility, with a significantly lower rate in California-Mexico and Peru (Fig. 3b; ANOVA: Region: $\left.F_{(4,24)}=96.62, \mathrm{p}<0.0001\right)$ and an effect of kinship detected only in Southern Chile and Magellan regions (Fig. S4 and Table S3; ANOVA: Breeding Type $\mathrm{x}$ Region: $\left.F_{(12,71)}=5.46, \mathrm{p}<0.0001\right)$. In the Atacama region, no effect of the male-female kinship was observed on either fecundity and fertility, even though average fecundity was similar to that detected in the Southern Chile and Magallanes regions (Fig. 3a). This pattern was explained by low fertilization rates in these regions (Fig. 3b). In Southern Chile-Los Lagos (LL), perennial and annual populations did not differ for any gametophyte trait except female length (Figs. S5, S6, S7, S8, S9 and Table S4, S5, S6, S7, S8). Comparison of morphological traits in juvenile sporophytes revealed larger blades and holdfasts in perennial populations, but no interaction with parental kinship $\mathrm{p}=0.77)$

DISCUSSION

Female fecundity and fertility are affected by male identity.

The presence of males and their kinship with females had a significant effect on different aspects of fecundity, including female size, number and size of oogonia. The phenomenon was highly consistent in showing higher values for females alone and in presence of their sib males, than with unrelated males. This effect was the result of the 
402 presence of male gametophytes, prior to any sexual contact between gametes, and 403 therefore strongly suggests that females can sense both the presence and the identity of 404 males. Sex-inducing pheromones have been described in many different algae, 405 including planktonic diatoms (Moeys et al. 2016), green algae and benthic macroalgae 406 (see review from Frenkel et al. 2014). Most of the identified molecules act as gamete 407 attractants, while some are considered sex inducers, as they trigger meiosis in diploids or the formation of gametes in haploids (Frenkel et al. 2014). In kelps, the only known sex pheromone is Lamoxirene, a molecule produced by the fertile female gametophyte which acts as an inducer of sperm release and attraction (Mamer et al. 1984). This single molecule is shared by all kelp species (Pohnert and Boland 2002), making it an unlikely candidate for kin recognition within species. Beyond that, there is no information about prezygotic allorecognition mechanisms in brown algae, such as those described in terrestrial plants or invertebrates. Our results suggest the existence of a more complex recognition system in Macrocystis, acting prior to gamete contact, allowing females to sense the presence and identity of males. It is possible that male 417 gametophytes release a blend of molecules that stimulate the female to behave 418 differently according to kinship. Alternatively, the chemical signaling may result from the bacterial biofilm associated with gametophytes. Growth stimulating hormones and morphogenetic compounds produced by microorganisms have been shown to be involved in the development of algae (Matsuo et al. 2005, Wichard 2015) and specific 422 bacteria are known to induce the synthesis of algal hormones such as auxins and 423 cytokinins (Lui et al. 2017, Dittami et al. 2014). Specific molecules released by associated bacteria are known to induce the production and posterior development of gametes in green algae (Frenkel et al. 2014). And bacteria may also be involved in pheromone degradation, therefore preventing gamete encounters due to outdated or non- 
target chemical cues (Cirri et al. 2018). There is growing interest in the properties of the holobiont (i.e. the algae and their interacting microorganisms forming a single entity; Egan et al. 2012). The microorganisms associated with Macrocystis gametophytes could well intercede in this recognition mechanism through an endogenous signaling system and remains to be explored.

Females left alone to induce parthenogenesis were the biggest in size and produced the highest number of gametes per capita. This might suggest that males actually inhibit female fecundity. Alternatively, it can be hypothesized that, in the absence of male chemical cues, females increase their size and fecundity in order to increase their pheromone production, as a compensating mechanism potentially increasing their attractiveness. This second hypothesis is more likely, as there would be no obvious ecological or evolutionary advantage for males to inhibit female fecundity. Interestingly, the presence of sib males had a similar (yet reduced) effect on females. Considering the hypothesis of chemical recognition of males discussed above, increased

441 female fecundity is therefore not only a consequence of the absence of males, but also 442 of appropriate males for successful fertilization. The rate of embryo per female gamete was the lowest for parthenogenetic females (with the exception of among-population intra-habitat crosses; see discussion below), followed by selfing and within-population crosses with a single male. A low rate of transformation of oogonia into embryos is expected if females could delay the parthenogenetic production of sporophyte progeny

447 as a way to extend the period of sexual pheromone production and male gamete attraction, saving the oogonia for the possibility of later fertilization. This is further supported by the observation that $<80 \%$ of oogonia produced embryos in parthenogenetic females, while females continued to produce new oogonia in the 
451 presence of males during the 5 days that separated the observations, and these were nearly all fertilized.

453 Reproductive success, although statistically different among breeding types, only varied 454 by 2.5-3 embryos per female. Although we found strong differences in fecundity, this 455 reduced variability in progeny number per female could be explained by a varying 456 fertilization rate of oogonia. Indeed, fecundity progressively diminished from 457 parthenogenetic to IntraPop2 (females with 2 different males from the same population), while the opposite trend was observed for embryogenesis rate. The reduced fertilization success associated with gametophyte kinship suggests, again, that allorecognition 460 mechanisms are operating. In brown algae, a gamete recognition system has been proposed in Ectocarpus siliculosus, determined by complementary surface carbohydrates located in the cell wall of the oogonia and sperm that are required for syngamy to occur (Schmid et al. 1994). Interestingly, a preference for outcrossing was found to be linked to a locus determining the capacity to induce parthenogenesis (Mignerot et al. 2019), suggesting that inbreeding avoidance and parthenogenesis are genetically linked. Therefore, it seems that increased fecundity is a response to the lack of genetically unrelated mates for ensuring stable reproductive success, as expected under the reproductive assurance hypothesis. And contrary to expectations under an inbreeding avoidance hypothesis, the gametophyte recognition mechanism did not appear to act as a prezygotic barrier, but rather as a way to increase the chances of successfully producing new sporophytes. Compensatory investment in female gametes when male gametes are limiting appears the predominant output of theoretical models of reproductive resource allocation (Gillet and Gregorius 2020). Such a plastic response of reproductive traits to sperm/pollen limitation or the relatedness of mates has been confirmed empirically in plants and animals (e.g. Tsitrone et al. 2003, Auld and Relyea 
476 2010). To our knowledge, this is the first report for algae characterised by a dioecious

477 haploid-diploid life cycle.

478 A notable exception to the observed pattern was found in the between-populations 479 within-habitat crosses, which behaved similar to parthenogenetic females in terms of the 480 number of oogonia and embryogenesis rate. It is noteworthy that this pattern was 481 evidenced in both experiments within the Southern Chile populations (InterPop 482 Experiment 1 and IntraHab - Experiment 2). On the contrary, female and oogonia size were significantly lower than parthenogenetic females. Following the hypothesis of 484 compensatory reproductive investment, it is possible that males from a different 485 population were not recognized as competent mates. This would be the case under a scenario of strong population divergence in chemical signals, which remains to be characterized. Such divergence would be expected among different habitats, either because of a divergence in the bacterial community of the holobiont, or because of a selection against admixed sporophytes due to outbreeding depression. Yet, betweenhabitat crosses did not follow the same pattern, by showing low fecundity and high 491 fertilization rates. This apparent contradiction of the results from the within- and between-habitat crosses is a question that remains unanswered, but it can be hypothesized to relate to the reproductive responses of females to specific chemical signals being driven by a suite of different mechanisms.

Inbreeding depression in the F1 diploid progeny.

The association of increased fecundity and reduced fertility represent a cost for female reproduction under inbreeding. However, the absolute number of embryos produced by parthenogenesis and selfing, under the laboratory conditions of the experiments, remained slightly higher than for outcrossing, suggesting an absence of inbreeding depression in the earliest stage of the diploid phase of $M$. pyrifera. These results differ 
501 from previously reported inbreeding depression in Californian populations (Raimondi et 502 al. 2004, Johansson et al. 2013, Gaylord et al. 2006). In laboratory and field 503 experiments, Raimondi et al. (2004) found that self-fertilization had strong negative 504 consequences on the fitness of $M$. pyrifera, as evidenced by a $40 \%$ decrease in zygote 505 production, a five times lower frequency of sporophytes reaching sexual maturity, and a 506 ten times reduction in reproductive tissue produced in selfed compared to outcrossed 507 progenies. A high mortality rate (i.e. $32 \%$ to $42 \%$ ) of inbred sporophytes was further 508 inferred from population genetic modelling (Johansson et al. 2013), explaining that few 509 highly homozygous individuals survive to adulthood. Our results on juvenile F1 510 sporophytes tend to be consistent with a lower early development (i.e. juvenile length,

511 holdfast size and number of blades) when comparing selfed versus outcrossed progenies 512 within populations. But the pattern did not strictly follow a negative correlation with the 513 inbreeding level, as parthenogenetic sporophytes were always bigger than selfed 514 progenies, and between-population crosses within habitat produced smaller sporophytes 515 than IntraPop2. Here, parthenogenesis was considered the highest possible level of 516 inbreeding, assuming the diploidization of the female gamete results in a fully 517 homozygous sporophyte. Further analysis of the process of parthenogenesis and the 518 developmental transition from gametophyte to sporophyte is required to better 519 understand the early performance of parthenogenetic sporophytes.

521 Kinship effect on fecundity and fertility of female gametophytes among different regions and habitats of the East Pacific coast.

523 Consistent with previous observations (Buschmann et al. 2004), low latitude 524 populations of both the northern and southern hemisphere had low fecundity and 
525 fertility of female gametophytes, compared to higher latitude populations in Chile.

526 Certainly, low latitude populations experience high temperatures, which is one of the 527 most important factors determining the distribution range limits of marine macroalgae 528 due to its effect on survival, growth and reproduction (Breeman 1988). The giant kelp, $529 M$. pyrifera is a cold temperate species, yet with a wide latitudinal range: from Alaska, 530 USA to Baja California, Mexico and from Peru to Cape Horn (Hoffmann and Santelices 1997, Graham et al. 2007). Light, temperature, and nutrients strongly vary across such a range, and therefore influence the metabolic tradeoff between vegetative growth or survival and reproduction. The significant interaction between regions and breeding types revealed that the effects of inbreeding were stronger in the Magallanes region than at the intermediate latitude of Southern Chile, and non-significant in Atacama, Peru and

536 California-Mexico. Therefore, low latitude females not only have a limited reproductive 537 capacity, but also a limited capacity to sense and respond to male kinship and inbreeding. This divergence was not observed between wave exposure habitats and perennial/annual demographics at the same latitude (i.e. Southern Chile). In this region, a genetic discontinuity and a morphological divergence was observed between these

541 two habitats (Camus et al. 2018). Sporophytes of annual populations produce more 542 spores per sorus area than in perennial populations (Buschmann et al. 2006). This strategy is believed to allow the establishment of a dense gametophyte population that will last the winter period when all sporophytes perish. A differentiation in gametophyte 545 reproductive traits was also expected because of the demographic differences, 546 considering that selfing is more common in annual than perennial populations (Barrett 547 et al. 1997) and that the evolution of resource allocation is influenced by both selfing 548 rate and the annual-perennial habit (Zhang 2000). It is likely that the drivers of the 549 reproductive divergence operate only at large spatial scales. 
550 The status of low-latitude populations may be defined by low nutrients associated with 551 warmer waters and competition with warm-tolerant species (Ladah et al. 1999, Steneck 552 et al. 2002, Graham et al. 2007). Moreover, these regions are subjected to recurrent El 553 Nino-Southern Oscillations and heat waves, which commonly result in widespread 554 mortality of the giant kelp, followed by recolonizations (Soto 1985, Tegner and Dayton 555 1987, Ladah et al. 1999, Edwards 2004, Vega et al. 2005, Cavanaugh et al. 2019). 556 Populations in such habitat at range margins tend to differ systematically from those in 557 central habitats in several demographic and reproductive characteristics (Kawecki 558 2008). Modifications of the mating system, such as increased asexual reproduction, has 559 been observed in terrestrial plants as a reproductive assurance strategy in marginal 560 populations (Eckert et al. 2006). Similar trends are observed in marginal kelp populations (Oppliger et al. 2011, 2014). According to Baker's law, selfing should be advantageous in populations characterized by recurrent extinction-recolonization (Pannel and Barret 1998) as it provides reproductive assurance when few progenitors 564 are contributing to the recolonization. In this context, a stronger compensatory effect on 565 female fecundity would be expected to maximize its fitness under a mixed mating system (Zhang 2000, Gillet and Gregorius 2020). However, considering the reduced fecundity and fertility observed in the marginal populations of $M$. pyrifera, it is possible that females evolved to mate with any male gamete, without requiring chemical recognition of kin males and differential investment in gametes.

570 In conclusion, the giant kelp, Macrocystis pyrifera, has the ability to reproduce 571 sexually and asexually (i.e. parthenogenesis) and with males of different levels of 572 kinship without major consequences in the fitness of females and their offspring. The 573 identified fecundity cost of selfing and parthenogenesis seems to efficiently compensate 574 for the reduced rate of embryo per oogonia, ultimately maintaining a slight but 
575 statistically significant fitness advantage over outcrossing. Confirming the existence and

576 identifying the nature of male chemical cues causing this differential response in high-

577 latitude females will be a key step to understand the drivers of this compensatory

578 resource allocation during gametophyte reproduction, and also to understand the

579 observed latitudinal differences. The trait might be a plastic response to environmental

580 heterogeneity. It is well-known that environmental factors, such as light quality and

581 quantity, temperature and nutrient concentrations greatly affect fertility and fecundity of

582 female gametophytes and embryonic sporophyte development (Lüning and Neushul

583 1978, Deysher and Dean 1984, 1986, Kinlan et al. 2003). What remains poorly

584 understood is the interaction of these abiotic factors with breeding types. However, the

585 observed latitudinal divergence while growing and reproducing in common garden

586 conditions suggests some heritable and/or epigenetic components that may have

587 consequences across diploid and haploid generations. In any case, questions emerge as

588 to whether the lack of kinship effects in low-latitude populations is an optimization of

589 the reproductive strategy under low fecundity/fertility or a maladaptation to marginal

590 environmental conditions. This may be particularly relevant as low latitude populations

591 of kelps are the most affected by ocean warming (Wernberg et al. 2018), and

592 conservation strategies, including restoration plans, should consider the optimal mating

593 strategy to secure long term demographic sustainability.

\section{ACKNOWLEDGEMENTS}

This work was financed by ANID/CONICYT FONDECYT de Iniciación N¹1170699

597 granted to C.C. and FONDECYT 1160930 to S.F and C.C, and EU-FP7 MARFOR 
600

601

602

603

604

605

606

607

608

609

610

611

612

613

614

615

616

617

618

619

620

621

622

623

sample processing in Mexico were undertaken on the following projects, CONACYT

CCC (The Coastal Complexity Crew) project number CB-2013-1, 221662, and UC

MEXUS-CONACYT.

\section{CONFLICT OF INTEREST}

Authors have no conflict of interest to declare.

\section{REFERENCES}

Auld, J. R. \& Relyea, R. A. 2010. Life-history plasticity and inbreeding depression under mate limitation and predation risk: cumulative lifetime fitness dissected with a life table response experiment. Evol. Ecol. 24:1171-1185.

Auld J.R. \& Rubio de Casas, R. 2013. The correlated evolution of dispersal and matingsystem traits. Evol. Biol. 40:185-193.

Barner, A.K., Pfister, C.A. \& Wootton, J.T. 2011. The mixed mating system of the sea palm kelp Postelsia palmaeformis: few costs to selfing. Proc. R. Soc. B 278: 1347-1355.

Barrett, S.C.H. \& Harder, L.D. 1996. Ecology and evolution of plant mating. Trends Ecol. Evol. 11: 73-79.

Barrett, S. C. H., Harder, L.D. \& Worley, A.C. 1997. The comparative biology of pollination and mating in flowering plants. In Silvertown, J., Franco, M. \& Harper, J.L. [Eds.] Plant life histories: ecology, phylogeny and evolution. Cambridge University Press, Cambridge, pp. 57-76.

Bates, D., Mächler, M., Bolker, B. \& Walker, S. 2015. Fitting linear mixed-effects models using lme4. J. Stat. Softw. 67: 1-48. 
Benzie J.A., Price I.R. \& Ballment E. 1997. Population genetics and taxonomy of Caulerpa (Chlorophyta) from the great barrier reef, Australia. J. Phycol. 33: 491504.

Billiard, S., López-Villavicencio, M., Hood, M.E. \& Giraud, T. 2012. Sex, outcrossing and mating types: unsolved questions in fungi and beyond. J. Evol. Biol. 25: 1020-1038.

Breeman, A.M. 1988. Relative importance of temperature and other factors in determining geographic boundaries of seaweeds: experimental and phenological evidence. Helgol. Meeresunters. 42:199-241 (1988).

Box, G.E. \& Cox, D.R. 1964. An analysis of transformations. J.R. Stat. Soc. Ser. B Methodol. 26, 211-252 (1964).

Busch, J.W. \& Delph, L.F. 2012. The relative importance of reproductive assurance and automatic selection as hypotheses for the evolution of self-fertilization. Ann. Bot. 109: 553-562.

Buschmann, A.H., Vásquez, J.A., Osorio, P., Reyes, E., Filún, L., Hernández-González, M.C. \& Vega, A. 2004. The effect of water movement, temperature and salinity on abundance and reproductive patterns of Macrocystis spp. (Phaeophyta) at different latitudes in Chile. Mar.Biol. 145: 849-862.

Buschmann, A.H., Moreno, C., Vásquez, J.A \& Hernández-González, M.C. 2006. Reproduction strategies of Macrocystis pyrifera (Phaeophyta) in southern Chile: The importance of population dynamics. J. App. Phycol. 18:575-582.

Camus, C., Faugeron, S. \& Buschmann, A.H. 2018. Assessment of genetic and phenotypic diversity of the giant kelp, Macrocystis pyrifera, to support breeding programs. Algal Res. 30: 101-112. 
Castric, V. \& Vekemans, X. 2004. Plant self-incompatibility in natural populations: a critical assessment of recent theoretical and empirical advances. Mol. Ecol. 13: 2873-2889.

Cavanaugh, K.C., Reed, D.C., Bell, T.W., Castorani, M.C.N. \& Beas-Luna, R. 2019. Spatial variability in the resistance and resilience of giant kelp in southern and Baja California to a multiyear heatwave. Front. Mar. Sci. 6:413.

Cirri, E., Vyverman, W. \& Pohnert, G. 2018. Biofilm interactions-bacteria modulate sexual reproduction success of the diatom Seminavis robusta. FEMS Microbiol. Ecol. 94: fiy161.

Charlesworth, D. \& Willis, J.H. 2009. The genetics of inbreeding depression. Nat. Rev. 10: 783-796.

Deysher, L.E. \& Dean, T.A. 1984. Critical irradiance levels and the interactive effects of quantum irradiance and dose on gametogenesis in the giant kelp, Macrocystis pyrifera. J. Phycol. 20: 520-524.

Deysher, L.E. \& Dean, T.A. 1986. In situ recruitment of sporophytes of the giant kelp, Macrocystis pyrifera (L.) C.A. Agardh: effects of physical factors. J. Exp. Mar. Biol. Ecol. 103: 41-63.

Dittami, S.M.T., Barbeyron, T., Boyen, C., Cambefort, J., Collet, G., Delage, L., Gobet, A., Groisillier, A., Leblanc, C., Michel, G., Scornet, D., Siegel, A., Tapia, J.E. \& Tonon, T. 2014. Genome and metabolic network of "Candidatus Phaeomarinobacter ectocarpi" Ec32, a new candidate genus of Alphaproteobacteria frequently associated with brown algae. Front. Genet. 5: 241. 
671 Druehl, L.D., Collins, J.D., Lane, C.D. \& Saunders, G.W. 2005. An evaluation of

672

673

674

675

676

677

678

679

680

681

682

683

684

685

686

687

688

689

690

691

692

693

694 methods used to assess intergeneric hybridization in kelp using Pacific Laminariales (Phaeophyceae). J. Phycol. 41: 250-262.

Eckert, C. G., Samis, K. E., \& Dart, S. 2006. Reproductive assurance and the evolution of uniparental reproduction in flowering plants. In Harder L.D. and Barrett S.C (Eds), Ecology and evolution of flowers, pp183-203.

Edwards, M.S. 2004. Estimating scale-dependency in disturbance impacts: El Niño and giant kelp forests in the northeast Pacific. Oecologia 138: 436-447.

Egan, S., Harder, T., Burke, C., Steinberg, P., Kjelleberg, S. \& Thomas, T. 2012. The seaweed holobiont: understanding seaweed-bacteria interactions. FEMS Microbiol. Rev. 37:462-476.

Engel, C. R., Destombe, C. \& Valero, M. 2004. Mating system and gene flow in the red seaweed Gracilaria gracilis: effect of haploid-diploid life history and intertidal rocky shore landscape on fine- scale genetic structure. Heredity 92:289-98.

Engel C.R., Daguin C. \& Serrao E.A. 2005. Genetic entities and mating system in hermaphroditic Fucus spiralis and its close dioecious relative F. vesiculosus (Fucaceae, Phaeophyceae). Mol. Ecol. 14:2033-2046.

Fox, J. 2002. An R and S-Plus companion to applied regression. SAGE Publications, Inc, $449 \mathrm{pp}$.

Frenkel, J., Vyverman, W. \& Pohnert, G. 2014. Pheromone signaling during sexual reproduction in algae. T. Plant J. 79: 632-644.

Gaylord, B., Reed, D.C., Raimondi, P.T., Washburn, L. \& McLean, S.R. 2002. A physically based model of macroalgal spore dispersal in the wave and currentdominated nearshore. Ecology, 83: 1239-1251. 
Gaylord, B., Reed, D.C., Raimondi, P.T. \& Washburn, L. 2006. Macroalgal spore dispersal in coastal environments: mechanistic insights revealed by theory and experiment. Ecol. Monogr. 76: 481-502.

Gillet, E. M. \& Gregorius, H. R. 2020. Effects of reproductive resource allocation and pollen density on fertilization success in plants. BMC ecology 20: 1-16.

Graham, M.H., Vásquez, J.A. \& Buschmann, A.H. 2007. Global ecology of the giant kelp Macrocystis: from ecotypes to ecosystems. Oceanogr. Mar. Biol. Annu. Rev. 45: 39-88.

Guillemin M.L., Valero M., Morales Collio K., Pinochet Sánchez R., Henríquez Espinosa M. \& Silva, A.X. 2016. Microsatellite markers and cytoplasmic sequences reveal contrasting pattern of spatial genetic structure in the red algae species complex Mazzaella laminarioides. J. Phycol. 52:806-816.

Hedrick, P.W. \& Garcia-Dorado, A. 2016. Understanding inbreeding depression, purging, and genetic rescue. Trends Ecol. Evol. 31: 940-952.

Hoffmann, A. \& Santelices, B. 1997. Flora marina de Chile central. Ediciones Universidad Católica de Chile, Santiago, 434 pp.

Hothorn, T., Bretz, F. \& Westfall, P. 2008. Simultaneous inference in general parametric models. Biom. J. 50: 346-363.

Jarne, P. \& Auld, J.R. 2006. Animals mix it up too: the distribution of self-fertilization among hermaphroditic animals. Evolution 60: 1816-1824.

Johansson, M.L., D.C., Raimondi, P.T., Reed, D.C., Coelho, N.C., Serrao, E.A. \& Alberto, F. 2013. Looking into the black box: simulating the role of selffertilization and mortality in the genetic structure of Macrocystis pyrifera. Mol. Ecol. 22: 4842-4854. 
Kawecki, T. J. 2008. Adaptation to marginal habitats. Annu. Rev. Ecol. Evol. Syst. $39: 21-42$

Kinlan, B. P. \& Gaines, S.D. 2003. Propagule dispersal in marine and terrestrial environments: a community perspective. Ecology 84: 2007-2020.

Kinlan, B.P., Grahamn M.H., Sala, E. \& Dayton, P.K. 2003. Arrested development of giant kelp (Macrocystis pyrifera, Phaeophyceae) embryonic sporophytes: a mechanism for delayed recruitment in perennial kelps? J. Phycol. 39:47-57.

Krueger-Hadfield, S.A., Collen, J., Daguin-Thiébaut, C. \& Valero, M. 2011. Genetic population structure and mating system in Chondrus crispus (Rhodophyta). J. Phycol. 52: 1-9.

Krueger-Hadfield, S.A., Roze, D., Mauger, S. \& Valero, M. 2013. Intergametophytic selfing and microgeographic genetic structure shape populations of the intertidal red seaweed Chondrus crispus. Mol. Ecol. 22: 3242-3260.

Ladah, L.B., Zertuche-Gonzalez, J.A. \& Hernández-Carmona, G. 1999. Giant kelp (Macrocystis pyrifera, Phaeophyceae) recruitment near its southern limit in Baja California after mass disappearance during ENSO 1997-1998. J. Phycol. 35:11061112.

Liu, X., Bogaert, K., Engeln, A.H., Leliaert, F., Roleda, M.Y. \& De Clerk, O. 2017. Seaweed reproductive biology: environmental and genetic controls. Bot. Mar. 60: 89-108.

Lüning, K. \& Neushul, M. 1978. Light and temperature demands for growth and reproduction of laminarian gametophytes in southern and central California. Mar. Biol. 45: 297-309. 
Maier, I., Hertweck, C. \& Boland, W. 2001. Stereochemical specificity of lamoxirene the sperm-releasing pheromone in kelp (Laminariales, Phaeophyceae). Biol. BullUS 201: 121-125.

Mamer F.J., Muller B. \& Jaenicke L. 1984. Lamoxirene. Structural proof of the spermatozoid releasing and attracting pheromone of Laminariales. Z. Naturforsch. C. 39: 689-691.

Matsuo, Y., Imagawa, H., Nishizawa, M. \& Shizuri, Y. 2005. Isolation of an algal morphogenesis inducer from a marine bacterium. Science 307: 1598.

McLachlan, J. 1973. Growth media. In Stein, J.R. [Ed.] Handbook of phycological methods, culture methods and growth measurements. Cambridge University Press, UK, pp. 25-52.

Mignerot, L., Avia, K., Luthringer, R., Lipinska, A.P., Peters, A.F., Cock, J.M. \& Coelho, S.M. 2019. A key role for sex chromosomes in the regulation of parthenogenesis in the brown alga Ectocarpus. PloS Genet. 15:e1008211.

Moeys, S., Frenkel, J., Lembke, C., Gillard, J.T.F., Devos, V., Van den Berge, K., Bouillon, B., Huysman, M.J.J., De Decker, S., Scharf, J., Bones, A., Brembu, T., Winge, P., Sabbe, K., Vuylsteke, M., Clement, L., De Veylder, L., Pohnert, G. \& Vyverman, W. 2016. A sex-inducing pheromone triggers cell cycle arrest and mate attraction in the diatom Seminavis robusta. Sci Rep 6: 19252.

Monteiro, C.A., Serrao, E.A. \& Pearson, G.A. 2012. Prezygotic barriers to hybridization in marine broadcast spawners: reproductive timing and mating system variation. PLOS ONE 7: e35978.

Müller, D.G., Murúa, P. \& Westermeier, R. 2019. Reproductive strategies of Lessonia berteroana (Laminariales, Phaeophyceae) gametophytes from Chile: Apogamy, 

1481.

768

769

Murúa, P., Edrada-Ebel, R.A., Muñoz, L., Soldatou, S., Legrave, N., Müller, D.G., Patiño, D.J., can West, P., Küpper, F.C., Westermeier, R., Ebel, R. \& Peters, A.F. 2020. Morphological, genotypic and metabolomic signatures confirm interfamilial hybridization between the ubiquitous kelps Macrocystis (Arthrothamnaceae) and Lessonia (Lessoniaceae). Sci. Rep. 10: 8279.

Olsen, K. C., Ryan, W.H., Winn, A.A., Kosman, E.T., Moscoso, J.A., KruegerHadfield, S.A., Burgess, S.C., Carlon, D.V., Grosberg, R.K., Kalisz, S. \& Levitan, D.R. 2020. Inbreeding shapes the evolution of marine invertebrates. Evolution 74, $871-882$.

Oppliger, L.V., Correa, J.A. \& Peters, A.F. 2007. Parthenogenesis in the brown alga Lessonia nigrescens (Laminariales, Phaeophyceae) from central Chile. J. Phycol. 43: 1295-1301.

Oppliger, L.V., Correa, J.A., Faugeron, S., Beltrán, J., Tellier, F., Valero, M. \& Destombe, C. 2011. Sex ratio variation in the Lessonia nigrescens complex (Laminariales, Phaeophyceae): Effect of latitude, temperature and marginality. $J$. Phycol. 47: 5-12.

Oppliger, L.V., Correa, J.A., Engelen, A.H., Tellier, F., Vieira, V., Faugeron, S., Valero, M., Gomez, G. \& Destombe, C. 2012. Temperature effects on gametophyte life-history traits and geographic distribution of two cryptic kelp species. PLOS One 7: 6.

Oppliger, L.V., von Dassow, P., Bouchemousse, S., Robuchon, M., Valero, M., J.A. Correa, Mauger, S. \& Destombe, C. 2014. Alteration of sexual reproduction and 
genetic diversity in the kelp species Laminaria digitata at the southern limit of its range. PLOS One 7: e102518.

Pannel, J.R. \& Barret, S.C.H. 1998. Baker's Law revisited: reproductive assurance in a metapopulation. Evolution 52: 657-668.

Perrin, C., Daguin, C., Van de Vliet, M., Engel, C.R., Pearson, G.A. \& Serrao, E.A. 2007. Implications of mating system for genetic diversity of sister algal species: Fucus spiralis and Fucus vesiculosus (Heterokontophyta, Phaeophyceae). Eur. J. Phycol. 42: 219-230.

Pinheiro, J.C. \& Bates, D.M. 2000. Mixed effects models in S and S-PLUS. SpringerVerlag, New York, Inc, 270 pp.

Pohnert, G. \& Bolard, W. 2002. The oxylipin chemistry of attraction and defense in brown algae and diatoms. Nat. Prod. Rep. 19: 108-122.

Puurtinen, M. 2011. Mate choice for optimal (K) inbreeding. Evolution 65: 1501-1505.

Raimondi, P.T., Reed, D.C., Gaylord, B. \& Washburn, L. 2004. Effects of selffertilization in the giant kelp, Macrocystis pyrifera. Ecology 85: 3267-3276.

Roze, D. 2016. Background selection in partially selfing populations. Genetics 203: 937-957.

San Miguel, R.A. 2017. Gametophyte fitness and costs of self-fertilization in the giant kelp, Macrocystis pyrifera. Capstone Projects and Master's Theses. California State University, Monterey Bay, 51 pp.

Santelices, B. 1990. Pattern of reproduction, dispersal and recruitment in seaweeds. Oceanogr. Mar. Biol. 28: 177-276.

Searle, S.R. 1987. Linear models for unbalanced data. Wiley \& Sons, New York, 536 pp. 
814 Schiel, D.R. \& Foster, M.S. 2015. The biology and ecology of giant kelp forest. $815 \quad$ University of California Press, $395 \mathrm{pp}$.

816 Schmid, C.E., Schroer, N.\& Müller, D.G. 1994. Female gamete membrane glycoproteins potentially involved in gamete recognition in Ectocarpus siliculosus (Phaeophyceae). Plant Sci. 102: 61-67.

Steneck, R.S., Graham, M.H., Bourque, B.J., Corbett, D., Erlandson, J.M., Estes, J.A. \& Tegner, M.J. 2002. Kelp forest ecosystems: Biodiversity, stability, resilience and future. Environ. Conserv. 29: 436-459.

822

Soto, R. 1985. Efectos del fenómeno El Niño 1982-83 en ecosistemas de la I Región. Investigaciones Pesquera (Chile) 32:199-206.

Szulkin, M., Stopher, K.V., Pemberton, J.M. \& Reid, J.M. 2013. Inbreeding avoidance, tolerance, or preference in animals? Trends Ecol. Evol. 28: 205-211.

Tegner, M.J. \& Dayton, P.K. 1987. El Niño effects on southern California kelps forest communities. Adv. Ecol. Res. 17: 243-279.

Teixeira, S., Pearson, G.A., Candeias, R., Madeira, C., Valero, M. \& Serrao, E.A. 2016. Lack of fine-scale genetic structure and distant mating in natural populations of Fucus vesiculosus. Mar. Ecol. Prog. Ser. 544: 131-142.

Tsitrone A, Jarne P \& David P. 2003. Delayed selfing and resource reallocation in relation to mate availability in the freshwater snail Physa acuta. Am. Nat. $162: 474-488$.

Vega, J.M.A., Vásquez, J.A. \& Buschmann, A.H. 2005. Population biology of the subtidal kelps Macrocystis integrifolia and Lessonia trabeculata (Laminariales, Phaeophyceae) in an upwelling ecosystem of northern Chile: interannual variability and El Niño 1997-1998. Rev. Chil. Hist. Nat. 78:33-50. 
Wernberg, T., Coleman, M.A., Bennet, S., Thomsen, M.D., Tuya, F. \& Kelaher, B.P. 2018. Genetic diversity and kelp forest vulnerability to climatic stress. Sci. Rep. $8: 1851$.

Westermeier, R., Patiño, D.J., Müller, H. \& Müller D.G. 2010. Towards domestication of giant kelp (Macrocystis pyrifera) in Chile: selection of haploid parent genotypes, outbreeding, and heterosis. J. Appl. Phycol. 22: 357-361.

Westermeier, R., Patiño, D. J., Murúa, P., Müller, D. G. 2011. Macrocystis mariculture in Chile: growth performance of heterosis genotype constructs under field conditions. J. App. Phycol. 23: 819-825.

Wichard, T. 2015. Exploring bacteria-induced growth and morphogenesis in the green macroalga order Ulvales (Chlorophyta). Front. Plant Sci. 6: 86.

Wooton, J.T.\& Pfister, C.A. 2013. Experimental separation of genetic and demographic factors on extinction risk in wild populations. Ecology 94: 2117-2123.

Yeo, I.K \& Johnson, R.A. 2000. A new family of power transformations to improve normality or symmetry. Biometrika 87 : 954-959.

Zhang, D.Y. 2000. Resource allocation and the evolution of self-fertilization in plants. Am. Nat. 155:187-199.

Zhao, X. B., Pang, S.J., Liu, F., Shan, T.F., Li, J., Gao, S.Q. \& Kim, H.G. 2016. Intraspecific crossing of Saccharina japonica using distantly related unialgal gametophytes benefits kelp farming by improving blade quality and productivity at Sanggou Bay, China. J. App. Phycol. 28: 449-455. 
864 Fig. 1: Map of sampling sites of Macrocystis pyrifera (black dots), with detailed location in 865 each sampling region. (a) California: Santa Cruz (SCR); and Mexico: Ensenada (ENS) and 866 Punta Baja (PBA). (b) Perú: Lima (LMA), Marcona (MRC), Ilo (ILO); and Atacama: Junin 867 (JNN), Caleta La Cuchara (LCU) and Antofagasta (ANT). (c) Southern Chile: Nilhue (NLH), 868 Pucatrihue (PUC) and Faro Corona (FCO). In the box, Southern Chile-Los Lagos (LL), where 869 triangles are perennial (Carelmapu and Pargua) and squares are annual (Ilque and Metri) 870 populations, respectively. (d) Magallanes: Puerto Natales (NAT), Faro San Isidro (FSI) and 871 Yartuo (YAR).

872 

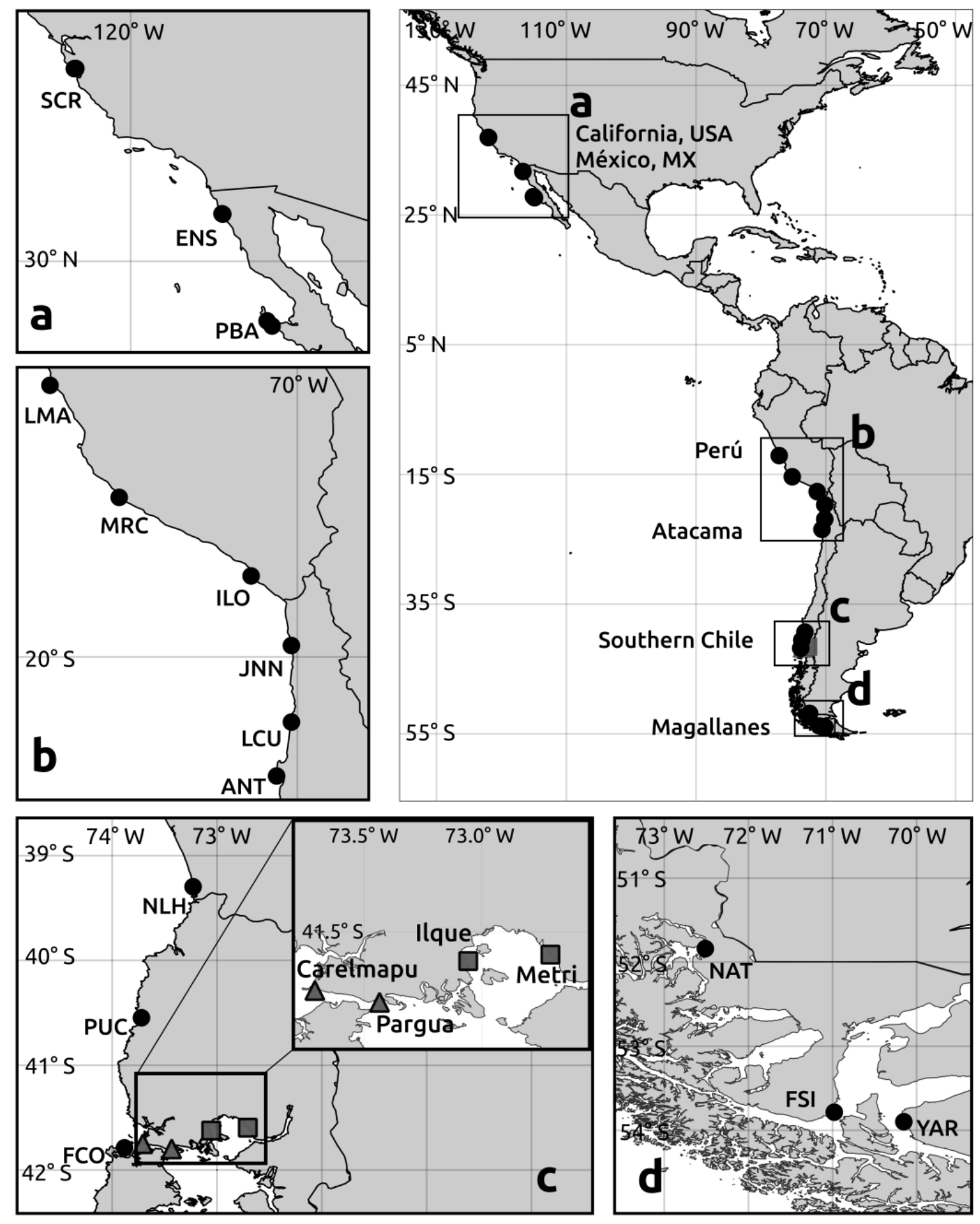
874 Fig. 2: Diagram of the workflow for the isolation of female and male gametophytes used for 875 crossing experiments. The progeny of each sampled sporophyte (top left) was handled 876 independently. Spores released from collected sporophylls were cultivated until germination and

877 differentiation into $\delta$ and $q$ gametophytes. These were isolated and cultivated separately and 878 fragmented into clonal filaments of 5 to 15 cells. For experiment 1, pools of clonal fragments 879 from 5 ㅇ gametophytes were established for each progeny. The same protocol was applied to $\overbrace{}^{\lambda}$. 880 Each pool was aliquoted into 4 units, to be used in the different breeding treatments: P: 881 parthenogenesis; S: selfing, exposing the $q$ pool to a $\delta$ pool issued from the same sporophyte; 882 IP5: intra-population outcross using a pool of $5 \mathrm{sib}$ ऽ issued from a different sporophyte of the 883 same population as the $q$ pool; IR: intra-region outcross using a $\delta$ pool issued from a 884 sporophyte from a different population but the same region. For experiment 2, single $q$ clones 885 were aliquoted into 4 units: IP1 and IP2 are intra-population outcross using a 1 or 2 cloned $\lesssim$, 886 respectively, issued from different sporophytes of the same population. Additionally, 887 interpopulation crosses were performed on $q$ pools issued from 13 different sporophytes, 888 crossed with $\delta$ pools issued from 13 different sporophytes of a different population and the 889 same habitat for intra-habitat crosses $(\mathrm{IH})$ or the alternative for between habitat crosses $(\mathrm{BH})$. 


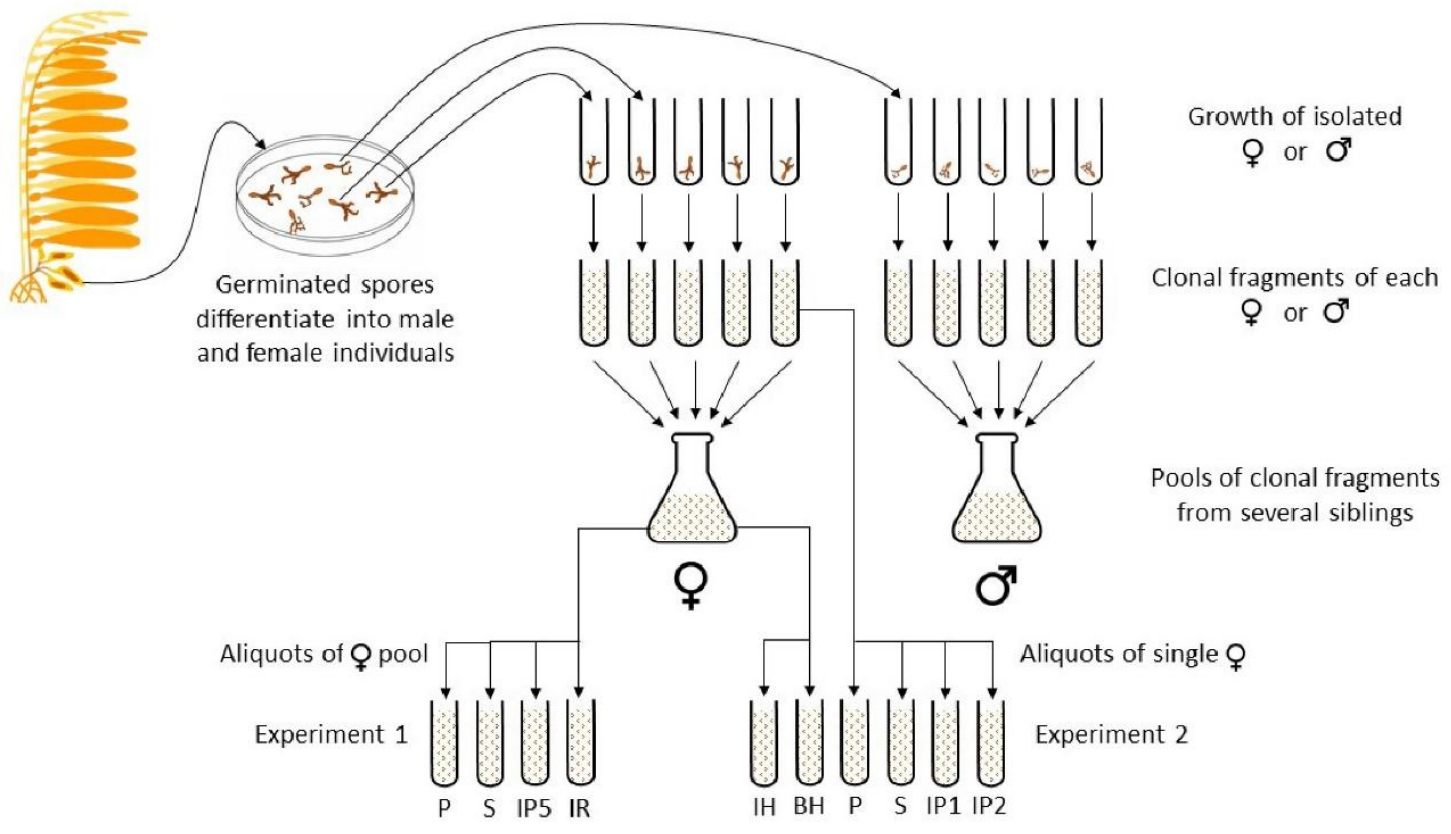


892 Fig. 3: Fecundity expressed as the number of oogonia per female gametophyte (a) and 893 embryogenesis rate (b) of females from California-Mexico, Perú, Atacama, Southern Chile and 894 Magallanes regions obtained in the different breeding types: parthenogenesis (P), selfing (S), 895 outcross within population (IntraPop5) and between populations of a same region (InterPop). 896 Letters represent statistical differences between treatments within each population.

897

898
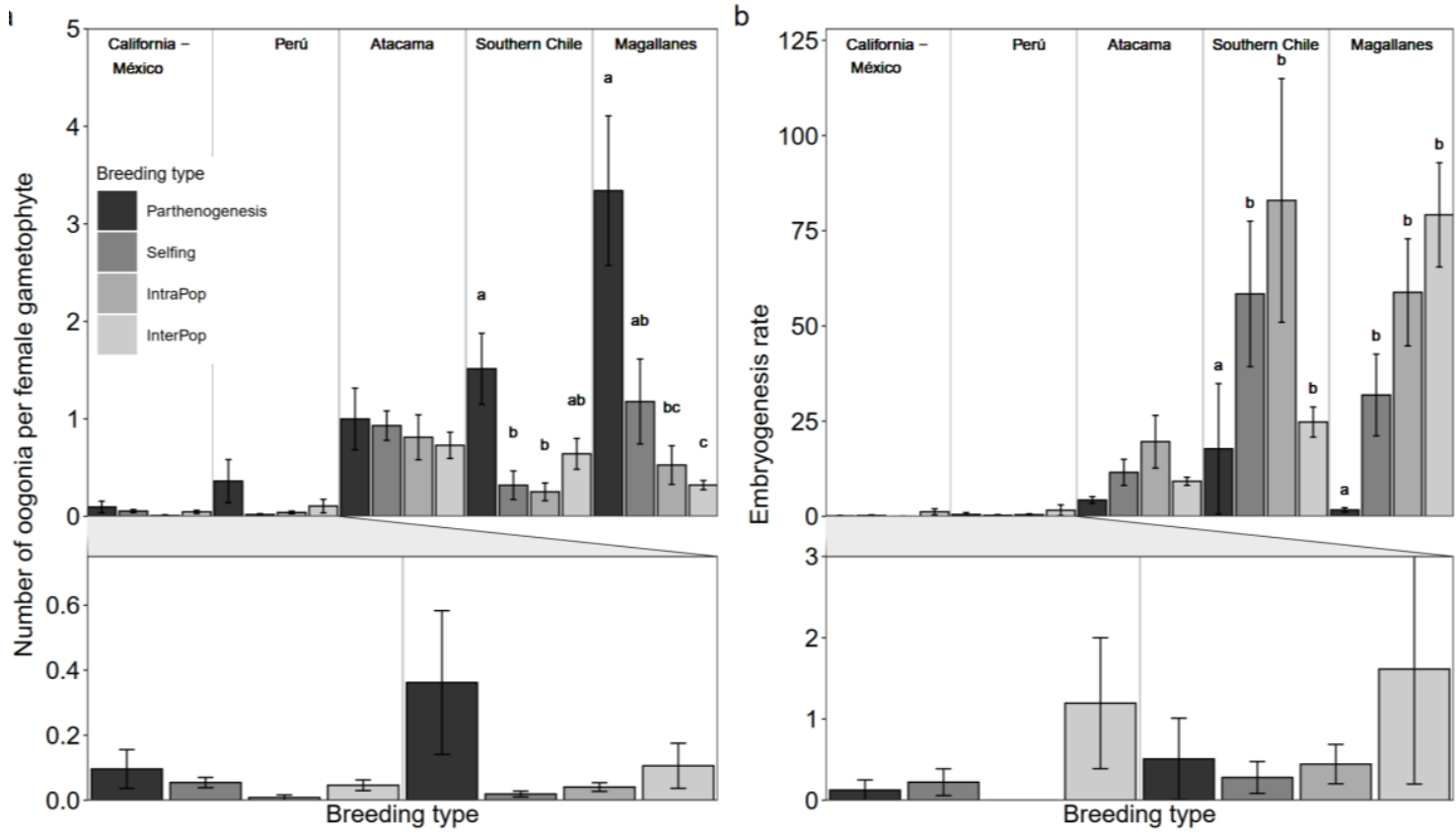
899 Fig. 4: Fecundity of female gametophytes from Southern Chile-Los Lagos (LL) populations, 900 expressed as the (a) number of oogonia per female gametophyte, (b) female gametophyte 901 length (mm) and (c) oogonia length; and fertility expressed as the (d) number of embryos per 902 female gametophyte and (e) embryogenesis rate obtained in the different breeding types: 903 parthenogenesis (P), selfing (S), outcross within population using 1 or 2 males (IntraPop1 and 904 IntraPop2, respectively), between populations of the same habitat (IntraHab) and between 905 habitats (InterHab). Letters represent statistical differences.
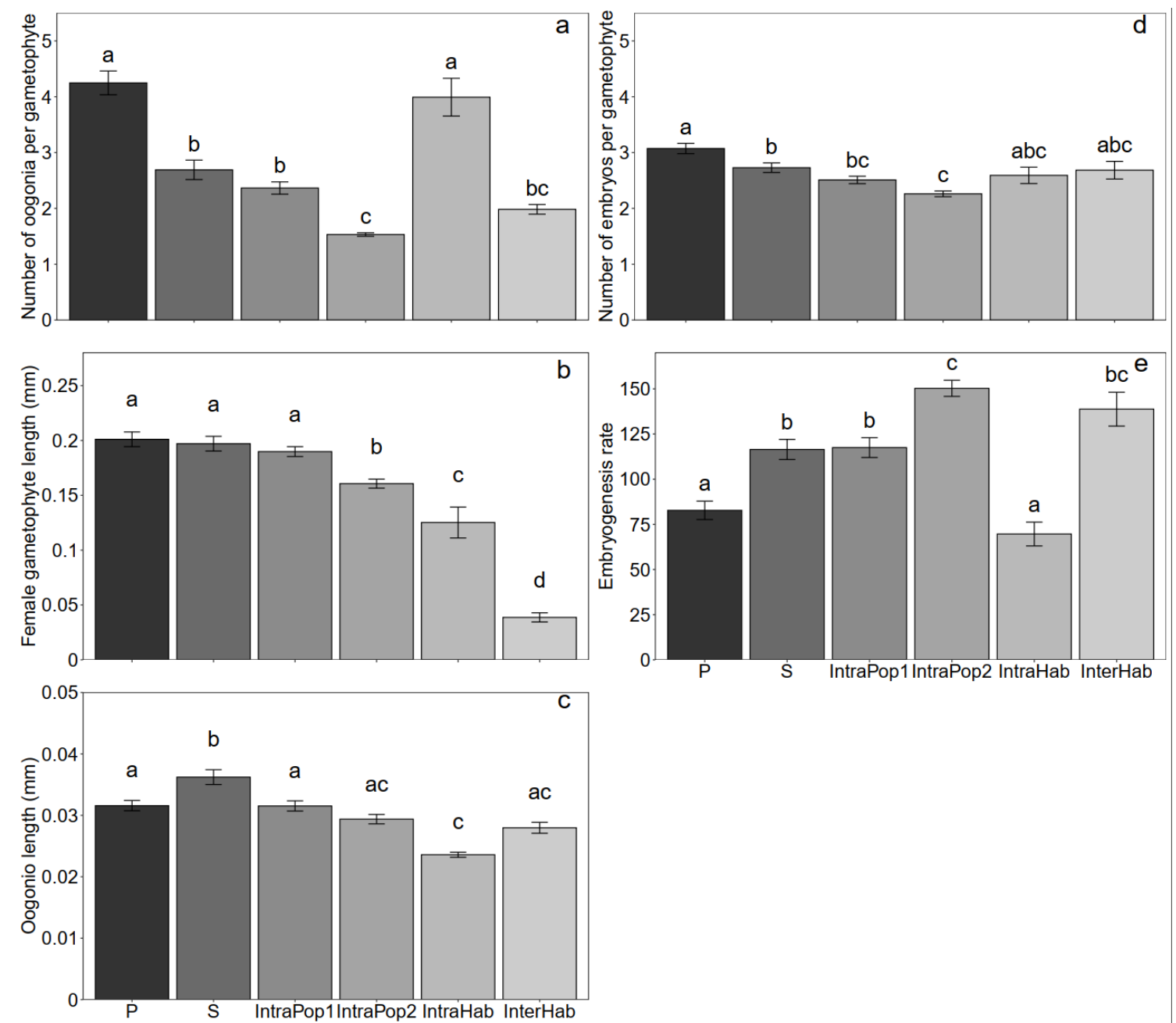
908 Fig. 5: Morphological characters evaluated on juvenile sporophytes from Southern Chile-Los

909 Lagos populations obtained in the different breeding types (see Fig. 4). (a) Sporophyte length

910 (mm). (b) number of blades per sporophyte. (c) Holdfast diameter (mm). Letters represent

911 statistical differences.

912 

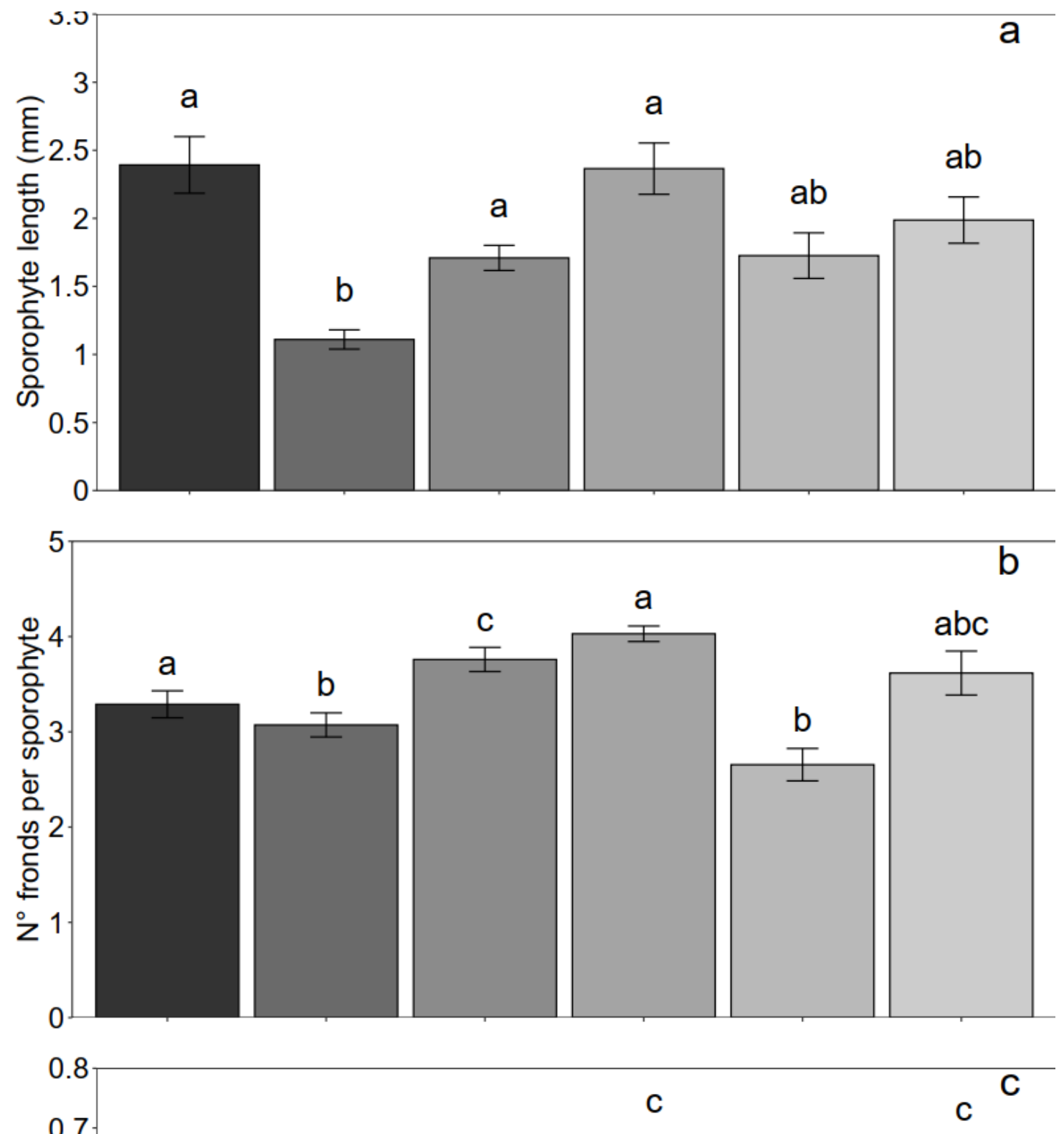

ह્ 0.6 Ф 0.5 ab
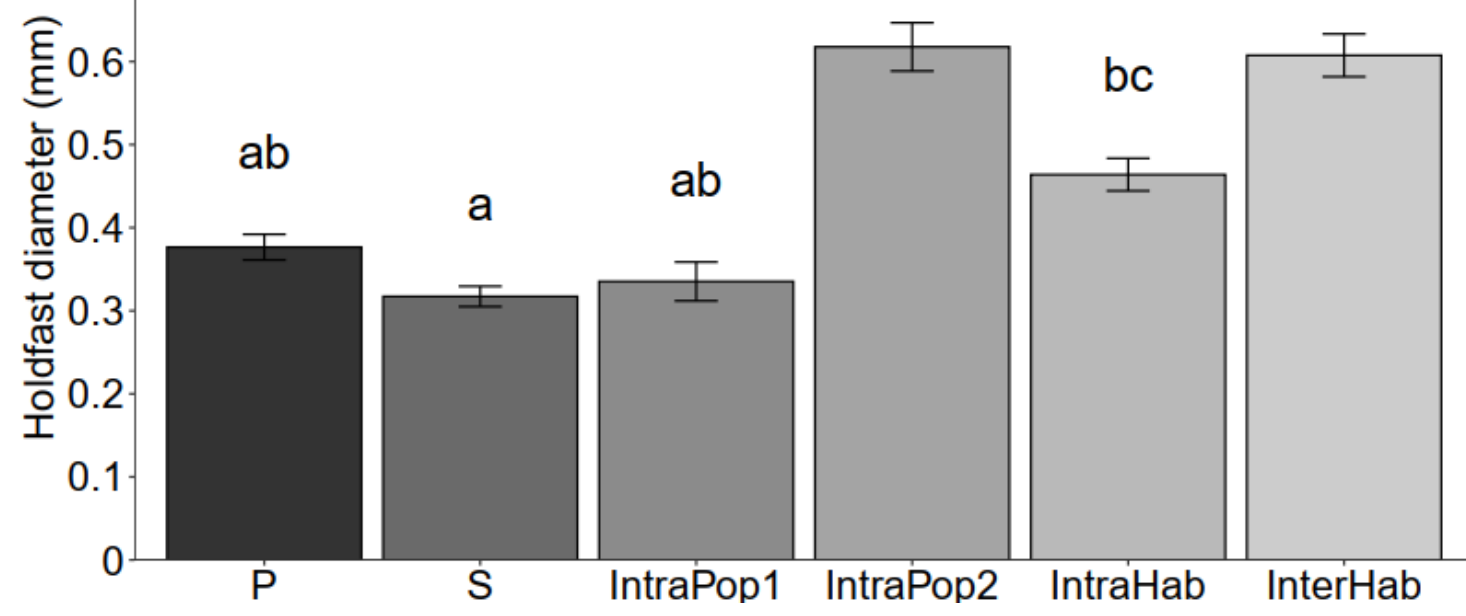
917

918 


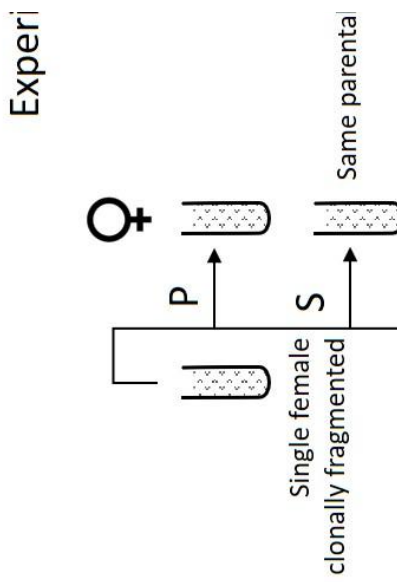

Figure S1. Diagram of the breeding types for experiment 1 and 2. P: parthenogenesis using single female pool (Experiment 1) or clone (Experiment 2), S: selfing using same parental sporophyte, IP5: intrapopulation cross using different parental sporophytes from the same population, IR:

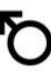
intra-region outcross using different parental sporophytes from

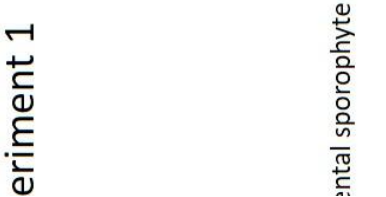
different populations, IP1 and IP2: intra-pop 1 cross using different parental sporophyte from the same population, IH: outcross

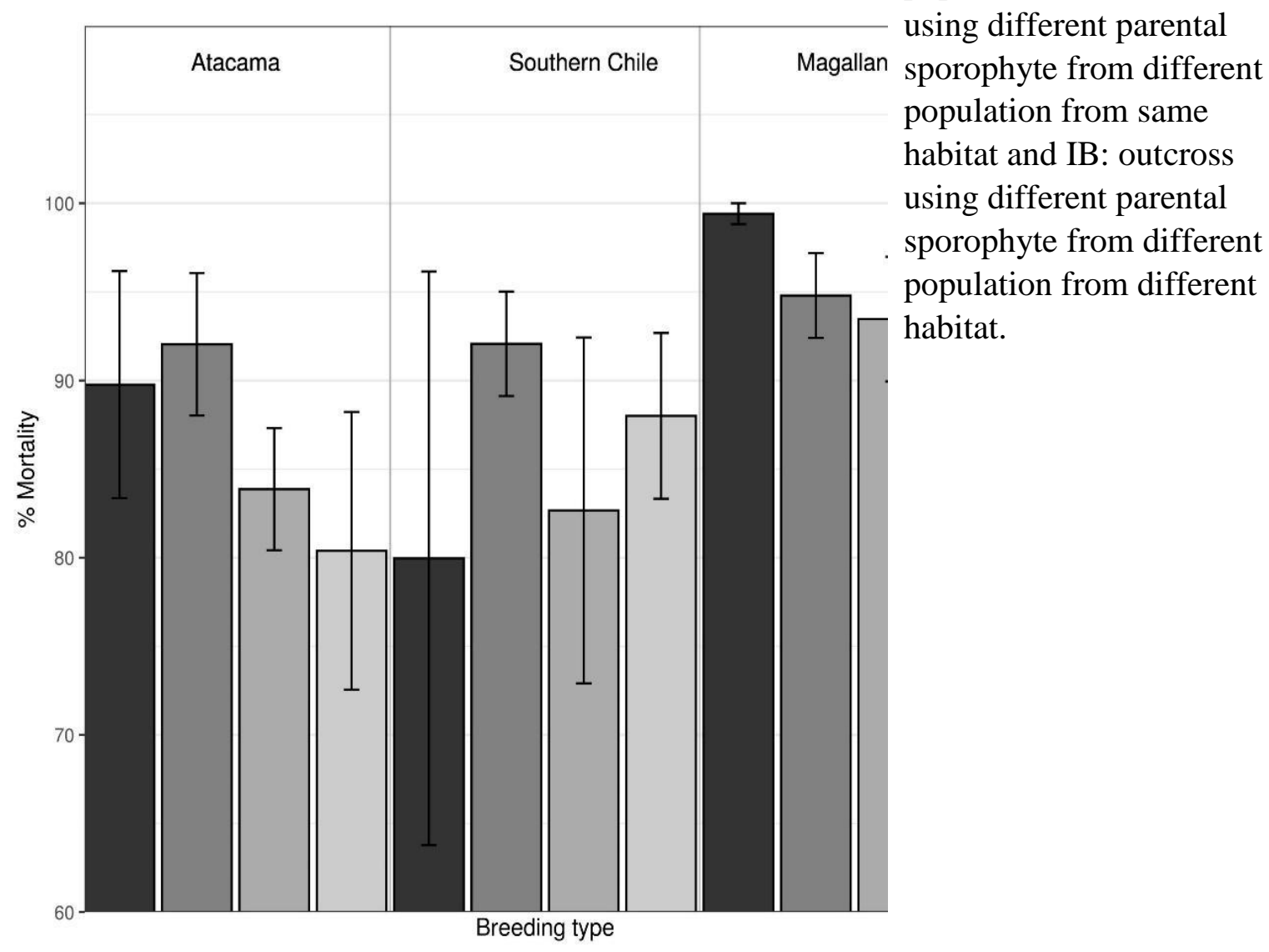


924 Figure S2. \% mortality of juvenile sporophytes from Atacama, Southern Chile and 925 Magallanes regions after exposure for 5 days to a heat wave of $24^{\circ} \mathrm{C}$ obtained in the 926 different breeding types: parthenogenesis (P), selfing (S), IntraPop5, and InterPop.

927

928 


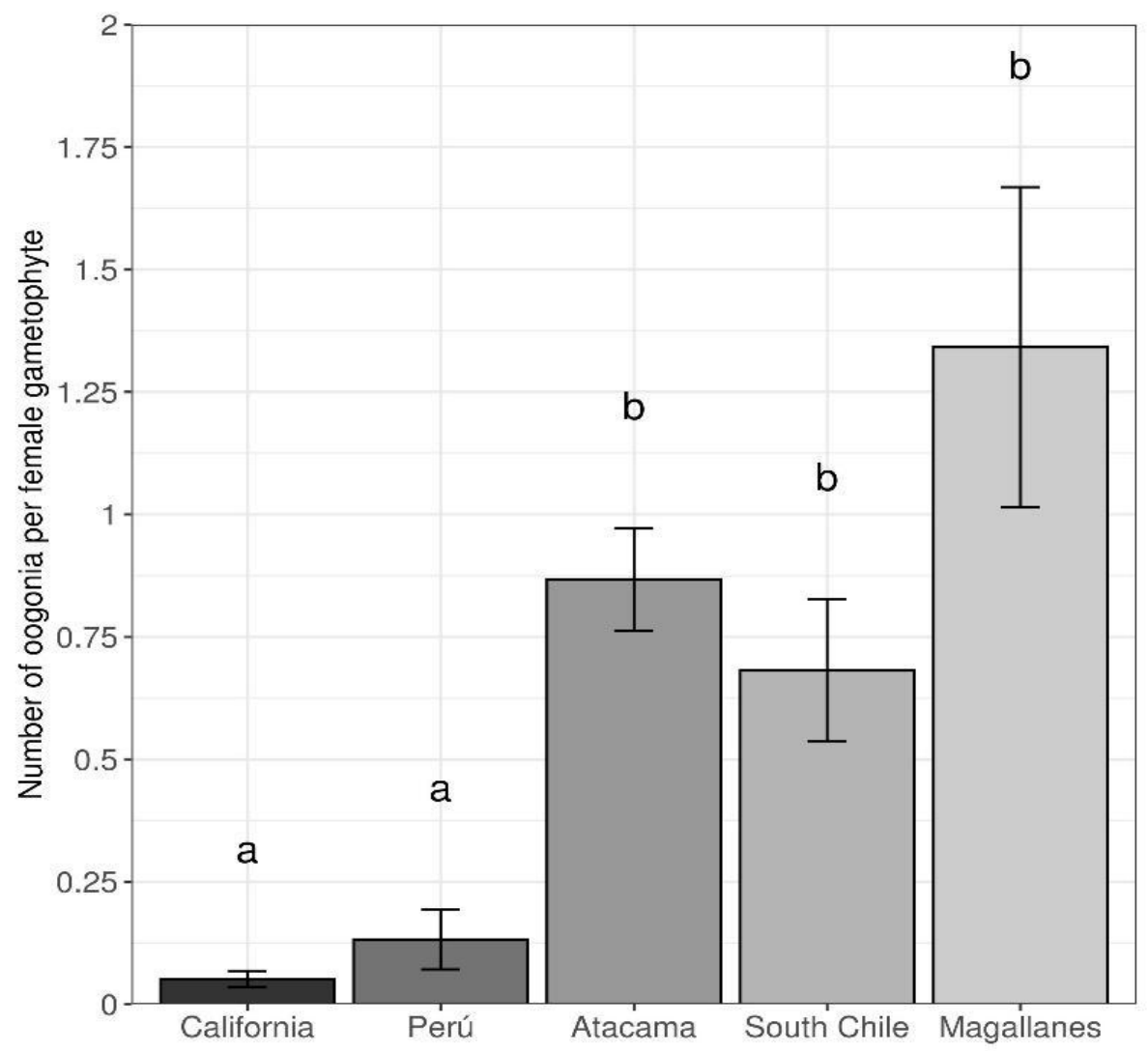

931 Figure S3. Fecundity expressed as the number of oogonia per female gametophyte from 932 California, Perú, Atacama, Southern Chile and Magallanes regions. Letters represent 933 statistical differences. 


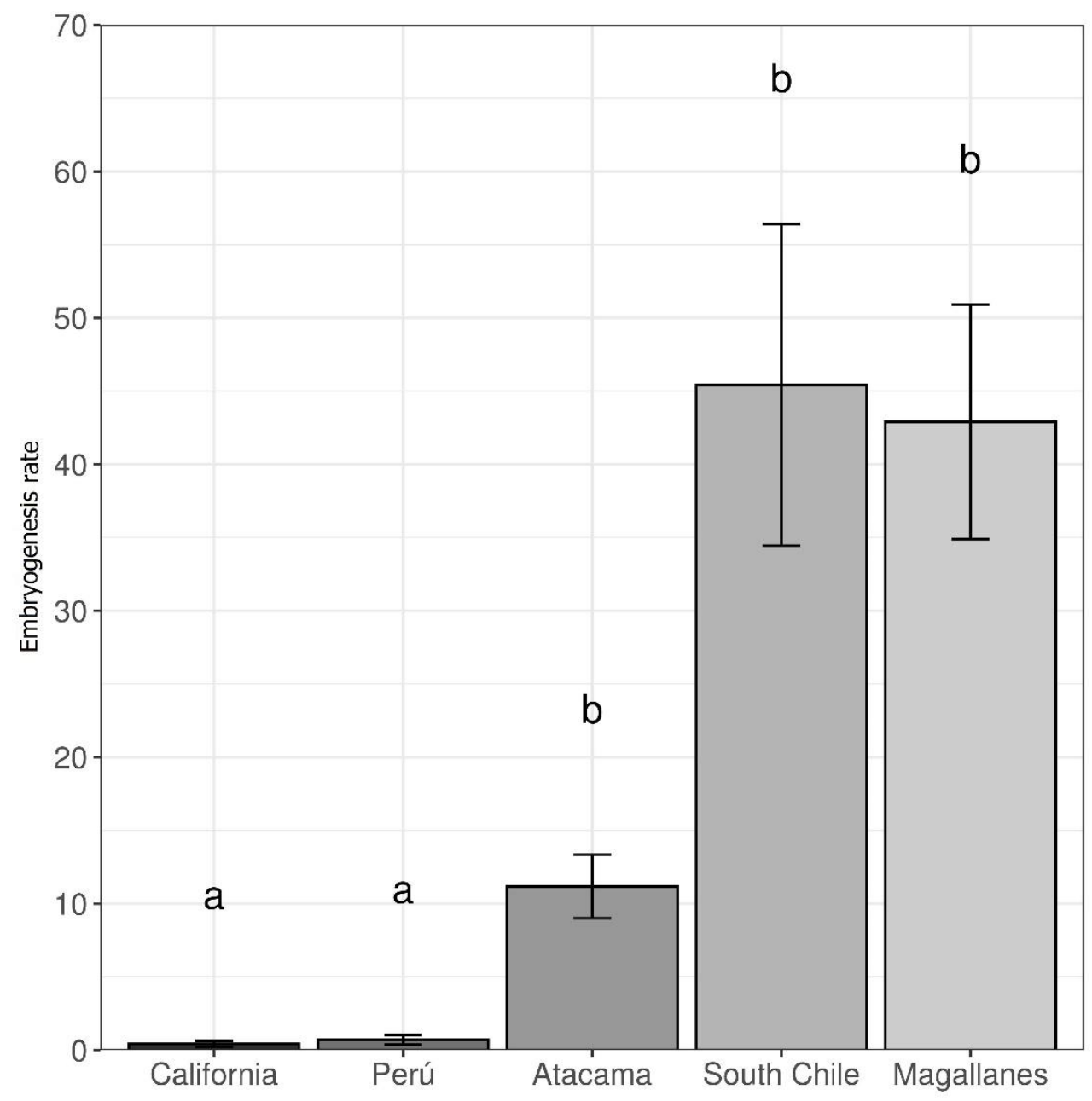

938 Figure S4. Embryogenesis rate of female gametophytes from California, Perú, 939 Atacama, Southern Chile and Magallanes regions. Letters represent statistical 940 differences.

941

942 


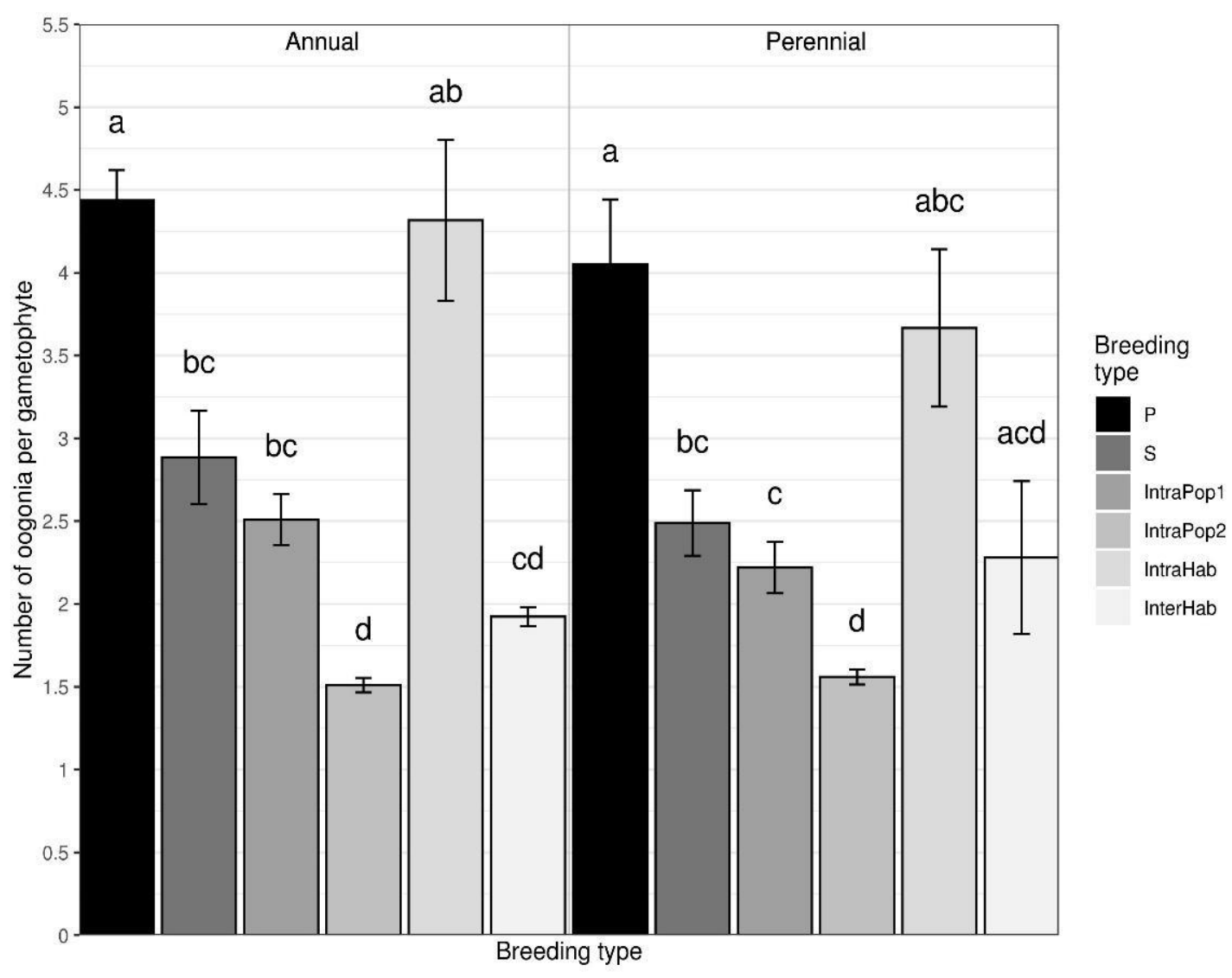

945 Figure S5. Number of oogonia per female gametophyte from annual and perennial 946 Southern Chile-Los Lagos populations obtained in different breeding types: 947 parthenogenesis (P), selfing (S), IntraPop1, IntraPop2, IntraHab and InterHab. Letters 948 represent statistical differences.

949 


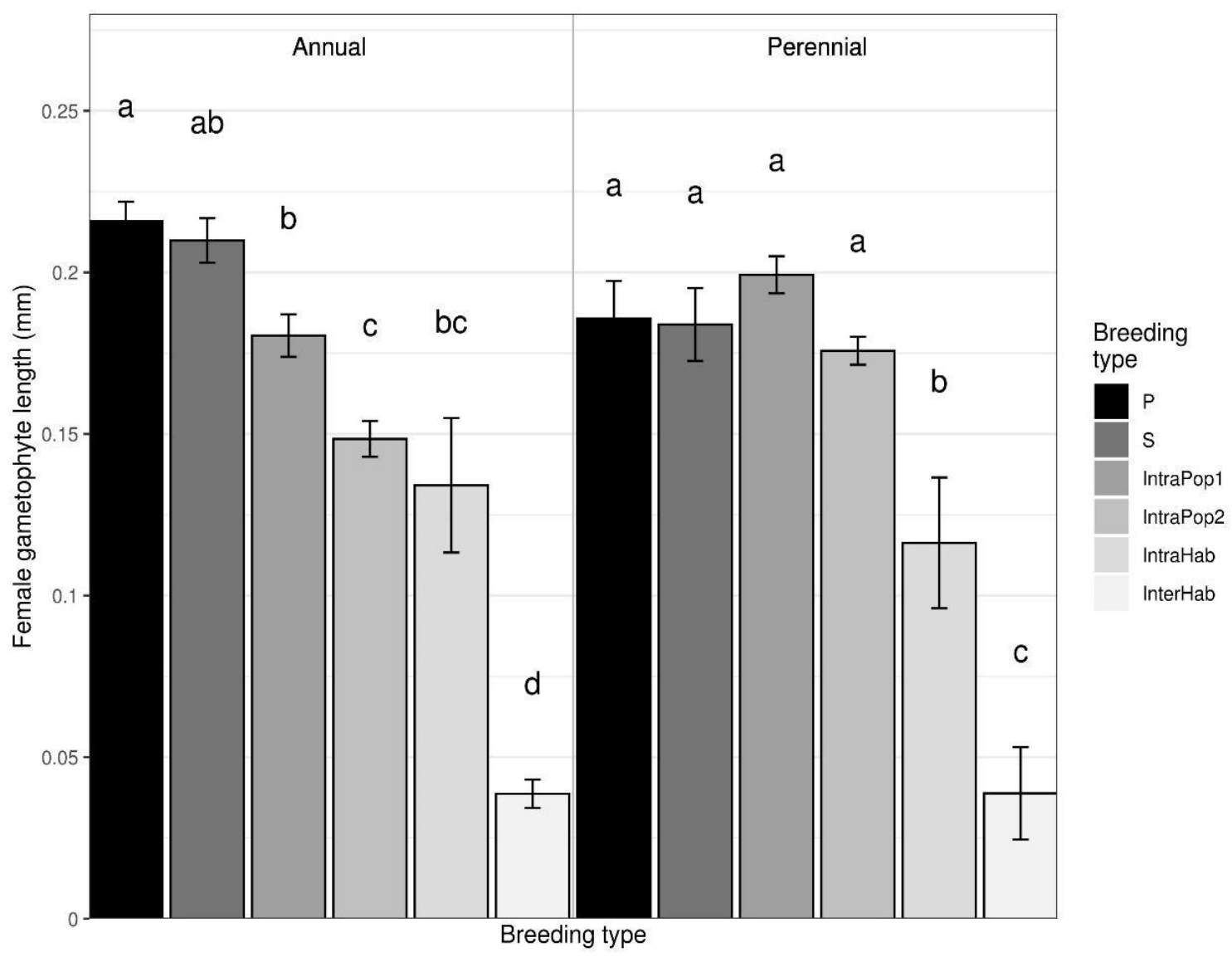

952

953 Figure S6. Female gametophyte length $(\mathrm{mm})$ from annual and perennial Southern 954 Chile-Los Lagos populations obtained in different breeding types: parthenogenesis (P), 955 selfing (S), IntraPop1, IntraPop2, IntraHab and InterHab. Letters represent statistical 956 differences.

957 


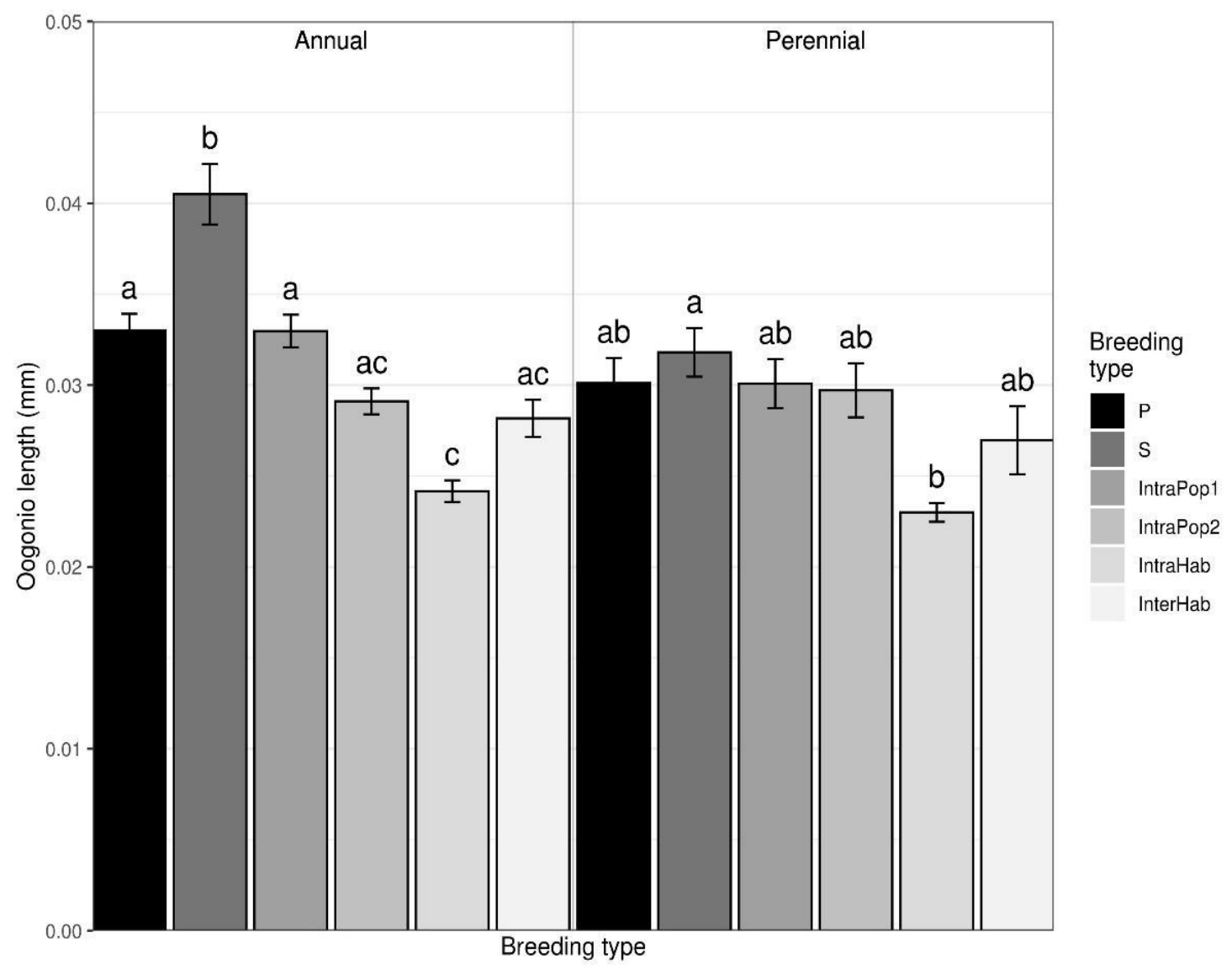

961 Figure S7. Oogonia length from annual and perennial Southern Chile-Los Lagos 962 populations obtained in different breeding types: parthenogenesis (P), selfing (S), 963 IntraPop1, IntraPop2, IntraHab and InterHab. Letters represent statistical differences.

964 


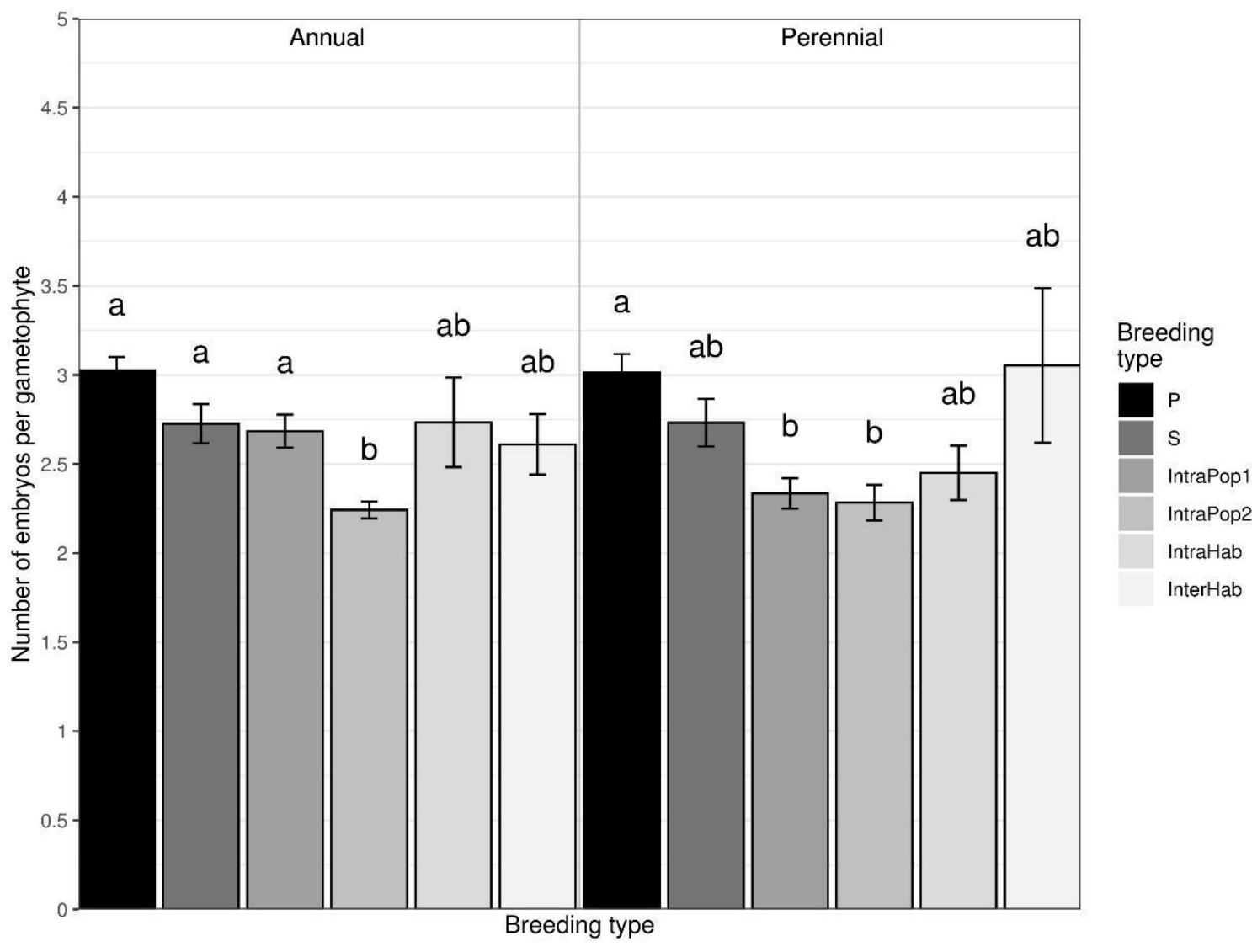

968 Figure S8. Number of embryos per female gametophyte from annual and perennial 969 Southern Chile-Los Lagos populations obtained in different breeding types: 970 parthenogenesis (P), selfing (S), IntraPop1, IntraPop2, IntraHab and InterHab. Letters 971 represent statistical differences.

972

973 


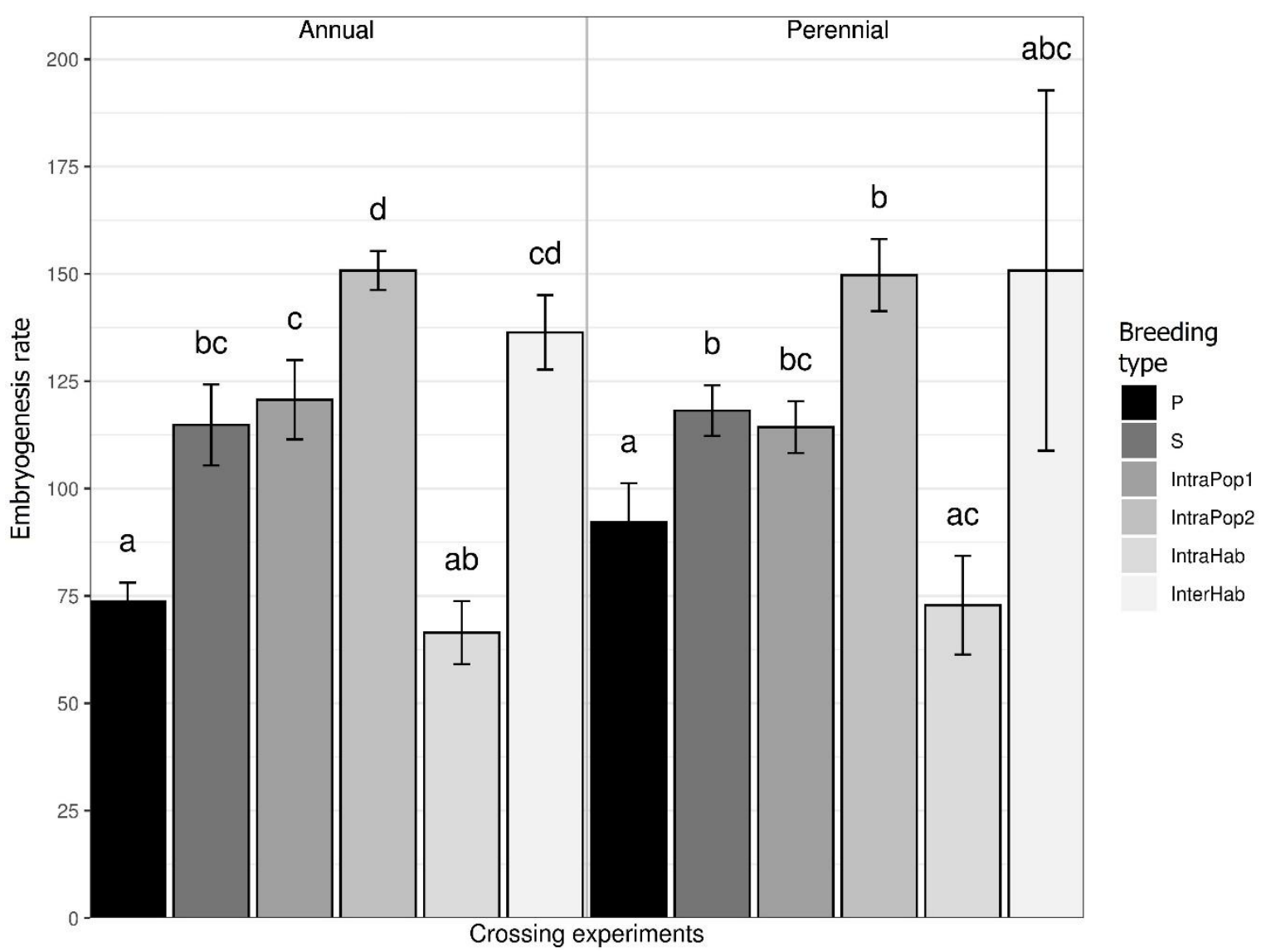

975

976 Figure S9. Embryogenesis rate from annual and perennial Southern Chile-Los Lagos

977 populations obtained in different breeding types: parthenogenesis (P), selfing (S),

978 IntraPop1, IntraPop2, IntraHab and InterHab. Letters represent statistical differences. 


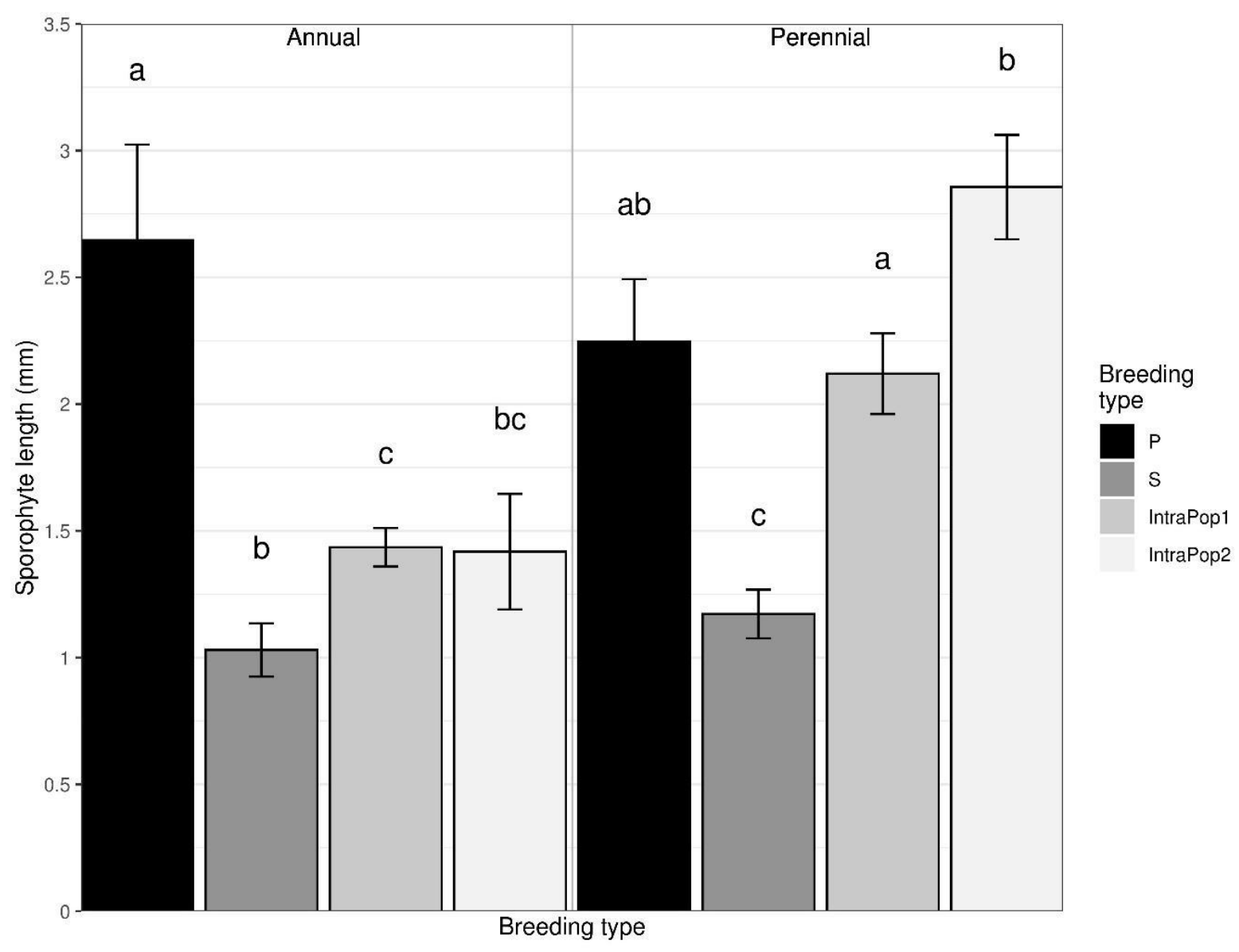

983 Figure S10. Sporophyte length $(\mathrm{mm})$ from annual and perennial Southern Chile-Los 984 Lagos populations obtained in different breeding types: parthenogenesis (P), selfing (S), 985 IntraPop1 and IntraPop2. Letters represent statistical differences.

986

987 


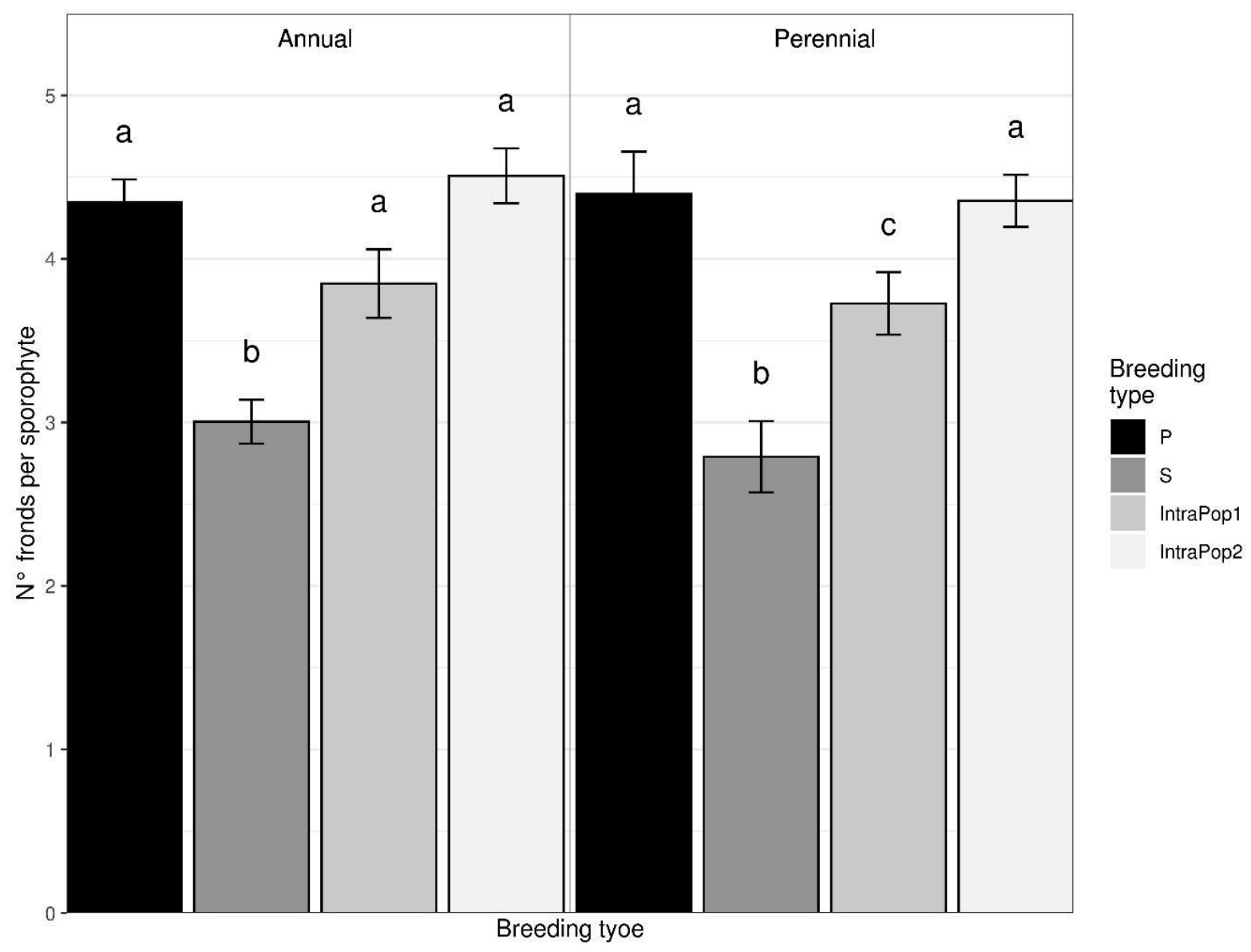

990 Figure S11. Number of fronds per sporophyte from annual and perennial Southern 991 Chile-Los Lagos populations obtained in different breeding types: parthenogenesis (P), 992 selfing (S), IntraPop1, IntraPop2, IntraHab and InterHab. Letters represent statistical 993 differences. 


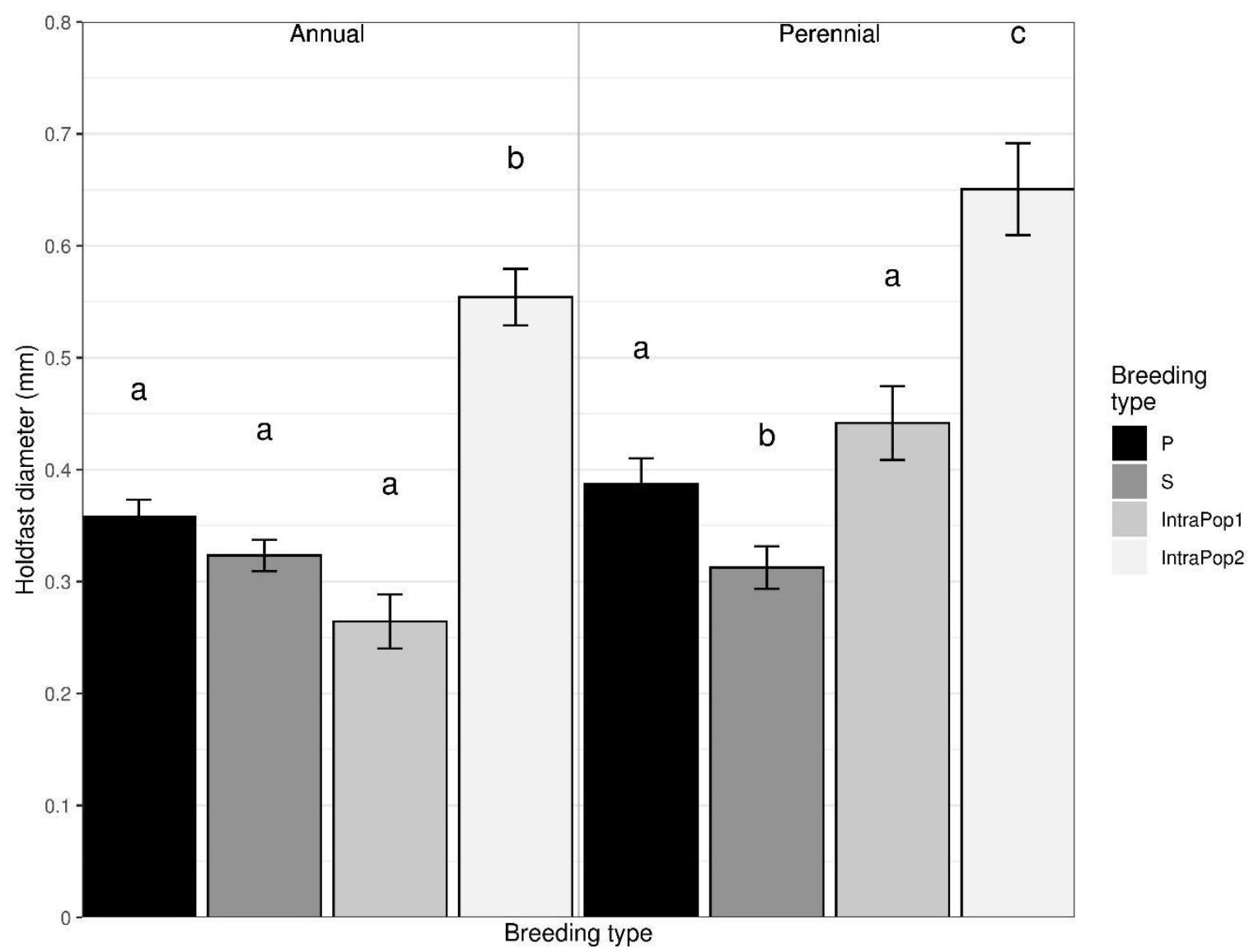

998 Figure S12. Holdfast diameter of sporophytes from annual and perennial Southern 999 Chile-Los Lagos populations obtained in different breeding types: parthenogenesis (P), 1000 selfing (S), IntraPop1, IntraPop2, IntraHab and InterHab. Letters represent statistical 1001 differences.

1002 
Table S1. Table of ANOVA results for the effect of breeding type (parthenogenesis,

1005 selfing, IntraPop5 and InterPop), region (Atacama, Southern Chile and Magallanes) and 1006 the interaction for the $\%$ mortality of juvenile sporophytes exposed for 5 days to a heat 1007 wave of $25^{\circ} \mathrm{C}$

\begin{tabular}{|l|l|l|l|l|l|l|}
\hline Fixed effects & SumSq & MeanSq & DF $_{\text {Num }}$ & DF $_{\text {Den }}$ & Fvalue & $\operatorname{Pr}(>\mathrm{F})$ \\
\hline Breeding type & 4.10 & 1.37 & 3 & 45 & 2.32 & 0.09 \\
\hline Region & 2.74 & 1.37 & 2 & 15 & 2.32 & 0.13 \\
\hline Breeding type:region & 1.93 & 0.32 & 6 & 45 & 0.54 & 0.77 \\
\hline
\end{tabular}

1008

1009

1010

Table S2. Table of ANOVA results for the effect of breeding type (Parthenogenesis,

1011 selfing, IntraPop5 and InterPop), region (California, Perú, Atacama, Southern Chile and

1012 Magallanes) and the interaction for fecundity express as the number of oogonia per

1013 female gametophyte.

\begin{tabular}{|l|l|l|l|l|l|l|}
\hline Fixed effects & SumSq & MeanSq & $\mathrm{DF}_{\text {Num }}$ & $\mathrm{DF}_{\text {Den }}$ & Fvalue & $\operatorname{Pr}(>\mathrm{F})$ \\
\hline Breeding type & 10.19 & 3.40 & 3 & 75 & 11.36 & $<0.0001$ \\
\hline Region & 54.71 & 13.68 & 4 & 25 & 45.76 & $<0.0001$ \\
\hline Breeding type:Region & 10.95 & 0.91 & 12 & 75 & 3.05 & 0.002 \\
\hline
\end{tabular}

1014 
Table S3. Table of ANOVA results for the effect of breeding type (Parthenogenesis,

1017 selfing, IntraPop5 and InterPop), region (California, Perú, Atacama, Southern Chile and 1018 Magallanes) and the interaction for fertilization rate.

\begin{tabular}{|l|l|l|l|l|l|l|}
\hline Fixed effects & SumSq & MeanSq & DF $_{\text {Num }}$ & DF $_{\text {Den }}$ & Fvalue & $\operatorname{Pr}(>\mathrm{F})$ \\
\hline Breeding type & 14.23 & 4.74 & 3 & 71 & 26.79 & $<0.0001$ \\
\hline Region & 68.44 & 17.11 & 4 & 24 & 96.62 & $<0.0001$ \\
\hline Breeding type:Region & 11.59 & 0.97 & 12 & 71 & 5.46 & $<0.0001$ \\
\hline
\end{tabular}

1019

Table S4. Table of ANOVA results for the effect of breeding type (Parthenogenesis, selfing, IntraPop1, IntraPop2, IntraHab and InterHab), habitat (annual: Ilque and Metri, perennial: Carelmapu and Pargua,) and the interaction for fecundity express as the number of oogonia per female gametophyte.

\begin{tabular}{|l|l|l|l|l|l|l|}
\hline Fixed effects & SumSq & MeanSq & $\mathrm{DF}_{\text {Num }}$ & $\mathrm{DF}_{\text {Den }}$ & Fvalue & $\operatorname{Pr}(>\mathrm{F})$ \\
\hline Breeding type & 108.27 & 21.65 & 5 & 108 & 48.40 & $<0.0001$ \\
\hline Habitat & 0.81 & 0.81 & 1 & 19 & 1.82 & 0.19 \\
\hline Breeding type:Habitat & 2.661 & 0.53 & 5 & 128 & 0.32 & 0.32 \\
\hline
\end{tabular}

Table S5. Table of ANOVA results for the effect of breeding type (Parthenogenesis, perennial: Carelmapu and Pargua,) and the interaction for fecundity express as female gametophyte length.

\begin{tabular}{|l|l|l|l|l|l|l|}
\hline Fixed effects & SumSq & MeanSq & DF $_{\text {Num }}$ & DF & Fvalue & $\operatorname{Pr}(>\mathrm{F})$ \\
\hline Breeding type & 41.48 & 8.30 & 5 & 124 & 11.55 & $<0.0001$ \\
\hline Habitat & 8.92 & 8.92 & 1 & 19 & 12.53 & 0.002 \\
\hline Breeding type:Habitat & 8.36 & 1.67 & 5 & 164 & 2.34 & 0.04 \\
\hline
\end{tabular}


Table S6. Table of ANOVA results for the effect of breeding type (Parthenogenesis, selfing, IntraPop1, IntraPop2, IntraHab and InterHab), habitat (annual: Ilque and Metri, perennial: Carelmapu and Pargua,) and the interaction for fecundity express as oogonia length.

\begin{tabular}{|l|l|l|l|l|l|l|}
\hline Fixed effects & SumSq & MeanSq & DF $_{\text {Num }}$ & DF $_{\text {Den }}$ & Fvalue & $\operatorname{Pr}(>\mathrm{F})$ \\
\hline Breeding type & 105.60 & 21.12 & 5 & 127 & 57.55 & $<0.0001$ \\
\hline Habitat & 0.15 & 0.15 & 1 & 19 & 0.42 & 0.53 \\
\hline Breeding type:Habitat & 9.36 & 1.87 & 5 & 172 & 5.12 & 0.0002 \\
\hline
\end{tabular}

1034

Table S7. Table of ANOVA results for the effect of breeding type (Parthenogenesis, selfing, IntraPop1, IntraPop2, IntraHab and InterHab), habitat (annual: Ilque and Metri, perennial: Carelmapu and Pargua,) and the interaction for fertility express as the number of embryos per gametophyte.

\begin{tabular}{|l|l|l|l|l|l|l|}
\hline Fixed effects & SumSq & MeanSq & $\mathrm{DF}_{\text {Num }}$ & $\mathrm{DF}_{\text {Den }}$ & Fvalue & $\operatorname{Pr}(>\mathrm{F})$ \\
\hline Breeding type & 46.78 & 9.36 & 5 & 126 & 11.94 & $<0.0001$ \\
\hline Habitat & 1.08 & 1.08 & 1 & 19 & 1.39 & 0.25 \\
\hline Breeding type:Habitat & 5.80 & 1.16 & 5 & 169 & 1.49 & 0.20 \\
\hline
\end{tabular}

Table S8. Table of ANOVA results for the effect of breeding type (Parthenogenesis, 1041 selfing, IntraPop1, IntraPop2, IntraHab and InterHab), habitat (annual: Ilque and Metri, 1042 perennial: Carelmapu and Pargua,) and the interaction for fertilization rate.

\begin{tabular}{|l|l|l|l|l|l|l|}
\hline Fixed effects & SumSq & MeanSq & DF $_{\text {Num }}$ & DF & Fvalue & $\operatorname{Pr}(>\mathrm{F})$ \\
\hline Breeding type & 75.78 & 15.16 & 5 & 117 & 24.88 & $<0.0001$ \\
\hline Habitat & 0.49 & 0.45 & 1 & 19 & 0.73 & 0.40 \\
\hline Breeding type:Habitat & 2.39 & 0.48 & 5 & 146 & 0.78 & 0.57 \\
\hline
\end{tabular}


Table S9. Table of ANOVA results for the effect of breeding type (Parthenogenesis, 1045 selfing, IntraPop1 and IntraPop2), habitat (annual: Ilque and Metri, perennial: Carelmapu and Pargua,) and the interaction for sporophyte length.

\begin{tabular}{|l|l|l|l|l|l|l|}
\hline Fixed effects & SumSq & MeanSq & DF $_{\text {Num }}$ & DF $_{\text {Den }}$ & Fvalue & $\operatorname{Pr}(>\mathrm{F})$ \\
\hline Breeding type & 41.93 & 13.98 & 3 & 145 & 34.61 & $<0.0001$ \\
\hline Habitat & 2.09 & 2.09 & 1 & 15 & 5.17 & 0.04 \\
\hline Breeding type:habitat & 10.56 & 3.52 & 3 & 145 & 8.71 & $<0.0001$ \\
\hline
\end{tabular}

1047

1048 Table S10. Table of ANOVA results for the effect of breeding type (Parthenogenesis, 1049 selfing, IntraPop1, IntraPop2, IntraHab and InterHab), habitat (annual: Ilque and Metri, 1050 perennial: Carelmapu and Pargua,) and the interaction for number of fronds per 1051 sporphyte.

1052

\begin{tabular}{|l|l|l|l|l|l|l|}
\hline Fixed effects & SumSq & MeanSq & $\mathrm{DF}_{\text {Num }}$ & $\mathrm{DF}_{\text {Den }}$ & Fvalue & $\operatorname{Pr}(>\mathrm{F})$ \\
\hline Breeding type & 56.40 & 18.80 & 3 & 147 & 33.85 & $<0.0001$ \\
\hline Habitat & 0.17 & 0.17 & 1 & 15 & 0.31 & 0.58 \\
\hline Breeding type:habitat & 0.93 & 0.31 & 3 & 147 & 0.56 & 0.65 \\
\hline
\end{tabular}

1053 Table S11. Table of ANOVA results for the effect of breeding type (Parthenogenesis, 1054 selfing, IntraPop1, IntraPop2, IntraHab and InterHab), habitat (annual: Ilque and Metri, 1055 perennial: Carelmapu and Pargua,) and the interaction for holdfast diameter of 1056 sporophytes.

\begin{tabular}{|l|l|l|l|l|l|l|}
\hline Fixed effects & SumSq & MeanSq & $\mathrm{DF}_{\text {Num }}$ & $\mathrm{DF}_{\text {Den }}$ & Fvalue & $\operatorname{Pr}(>\mathrm{F})$ \\
\hline Breeding type & 64.93 & 26.23 & 3 & 114 & 41.23 & $<0.0001$ \\
\hline Habitat & 1.82 & 1.82 & 1 & 16 & 4.65 & 0.05 \\
\hline Breeding type:habitat & 7.86 & 1.96 & 3 & 114 & 4.99 & 0.0009 \\
\hline
\end{tabular}

